Check for updates

Cite this: RSC Adv., 2018, 8, 16997

\title{
1,2,3-Triazole-fused spirochromenes as potential anti-tubercular agents: synthesis and biological evaluation $\dagger$
}

\author{
Dongamanti Ashok, (DD *a Pamula Chiranjeevi, ${ }^{\text {a }}$ Aamate Vikas Kumar, ${ }^{a}$ \\ Madderla Sarasija, ${ }^{\mathrm{b}}$ Vagolu Siva Krishna, ${ }^{\mathrm{C}}$ Dharmarajan Sriram ${ }^{\mathrm{C}}$ \\ and Sridhar Balasubramanian ${ }^{d}$
}

A facile and convenient approach has been designed for the synthesis of novel prototypes that possess the advantage of the two pharmacophores of chromene and 1,2,3-triazole in a single molecular backbone, were evaluated against Mycobacterium tuberculosis H37Rv strain. The new analogues 1,2,3-triazolefused spirochromenes were accomplished in four step synthetic strategy utilizing click chemistry ([3 +2$]$ Huisgen cycloaddition) in the ultimate step. The synthesized compounds were established based on the spectral data and X-ray crystal structure for 7a. Among the compounds tested against Mycobacterium tuberculosis H37Rv strain, some products exhibited potent antimycobacterial activity with minimum inhibitory concentration (MIC) values ranging from 1.56 to $6.25 \mu \mathrm{g} \mathrm{m}^{-1}$. Compounds exhibiting good in vitro potency in the MTB MIC assay were further examined for cytotoxicity in a RAW 264.7 cells. Compounds 7a, 7d, 7i (MIC: $1.56 \mu \mathrm{g} \mathrm{mL}^{-1}$ ) and 7k, 7m (MIC: $3.125 \mu \mathrm{g} \mathrm{mL}^{-1}$ ) exhibited promising hits.

Received 14th April 2018

Accepted 26th April 2018

DOI: 10.1039/c8ra03197e

rsc.li/rsc-advances chemical entities provided with promising antimycobacterial activities. $^{7}$

Chromene (benzopyran), an important class of benzo-fused oxaheterocycles is an integral part of many bioactive compounds exhibiting a wide range of biological properties including anti-HIV, ${ }^{8-10}$ anticancer, ${ }^{11,12}$ antimicrobial, ${ }^{13,14}$ antitumor, ${ }^{15}$ antiviral, ${ }^{16}$ anti-inflammatory ${ }^{17}$ and antioxidant ${ }^{18}$ activities. Among naturally occurring chromene heterocycles, molecules like dehydrolupinifolinol (I), eriosemaone A (II), karanjachromene (III), (+)-calanolide A (IV) and benzofurochromene (V) were reported as anti-tubercular agents (Fig. 1). ${ }^{19-22}$ On the other hand, synthesis of triazole-fused compounds approached through click reaction continues to fascinate the attention of chemists, in a bid to identify molecules with enhanced pharmacological properties. ${ }^{23}$ Moreover, compounds consisting 1,2,3-triazole ring fused with various carbocyclic moieties exhibited remarkable biological activities, e.g., 1,2,3-triazolo[1,5-a]quinoxaline possess good affinity toward benzodiazepine and adenosine receptors ${ }^{24,25}$ and the morpholine-fused triazole is efficient $\gamma$-secretase modulator (GSM) for the treatment of Alzheimer's disease. ${ }^{26}$ Additionally, 1,2,3-triazoles conjugated with different sorts of heterocyclic moieties were reported to exhibit potent anti-tubercular activity (VI-XI) (Fig. 2)..$^{27-30}$

Therefore the triazole-fused structural motifs became increasingly common in pharmaceutical targets and in a wide array of bioactive molecules such as chemotherapeutic $\mathbf{A},{ }^{31}$ antibacterial $\mathbf{B}^{32}$ and cardiovascular $\mathbf{C}^{33}$ agents (Fig. 3). Inspired by the frequent occurrence of 1,2,3-triazole or 
<smiles>CC(C)=CCc1c2c(c(O)c3oc(-c4ccc(O)cc4)c(O)c(=O)c13)C=CC(C)(CI)O2</smiles>

Dehydrolupinifolinol

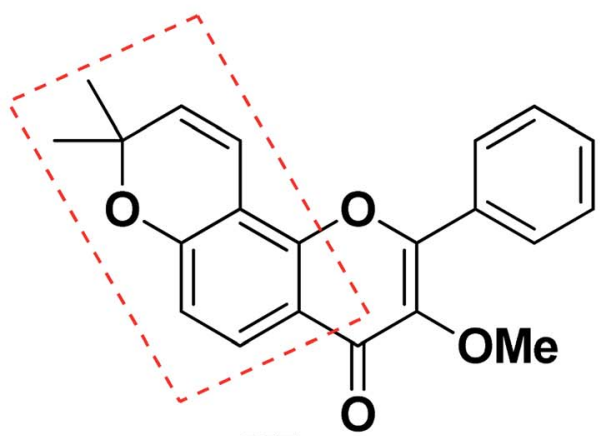

III

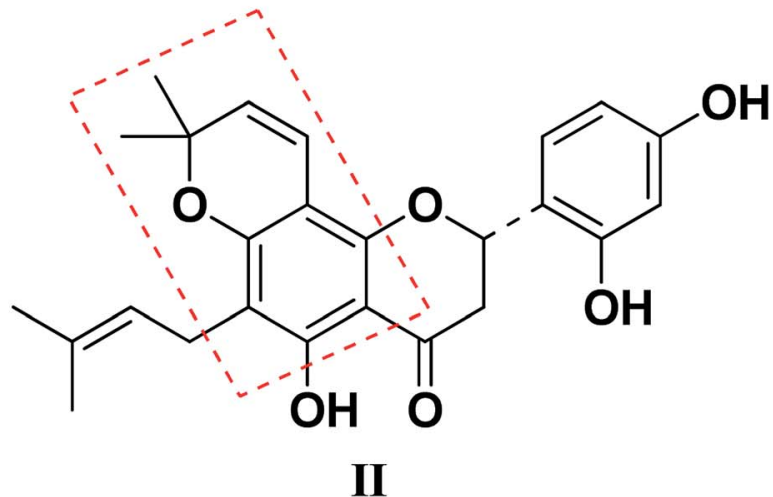

Eriosemaone A<smiles>CCCc1cc(=O)oc2c(I)c3c(c(C(C)C)c12)OC(I)(I)C=C3</smiles>

(+)-Calanolide A

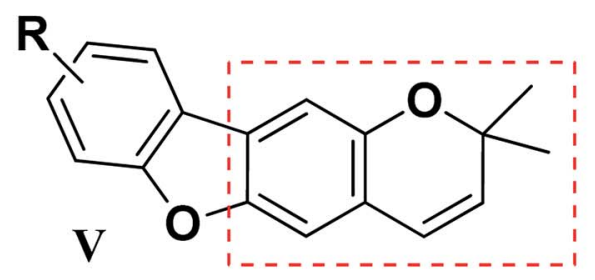

\section{Benzof uro-chromene}

Fig. 1 Chromene based inhibitors reported as antimycobacterial agents.

chromene framework in various biologically active antitubercular agents and in continuation to our ongoing efforts $^{34,35}$ in exploiting the biological significance of 1,2,3triazole nuclei fused with various carbocyclic frameworks, we anticipated that integration of these two frameworks in a single molecule may provide truly effective lead structures (Fig. 4) and they are further evaluated against the Mycobacterium tuberculosis $\mathrm{H} 37 \mathrm{Rv}$ strain. To the best of our knowledge, synthesis and antimycobacterial activities of these 1,2,3triazole-fused spirochromene conjugates are unprecedented.

\section{Results and discussion}

\section{Chemistry}

The strategy adopted for synthesis of 1,2,3-triazole-fused spirochromene scaffolds, is depicted in Scheme 1. In the first step, Kabbe condensation of substituted acetophenones 1a-c with 1,4-dioxaspiro[4.5]decan-8-one 2 , in the presence of pyrrolidine gave corresponding dispiro[chromane-2, $1^{\prime}$-cyclohexane- $4^{\prime}, 2^{\prime \prime}$ $[1,3]$ dioxolan]-4-ones $\mathbf{3 a - c} .^{36,37}$ Subsequently, these were subjected to reduction using sodium borohydride $\left(\mathrm{NaBH}_{4}\right)$ to afford the spirochromanols $\mathbf{4 a - c .}{ }^{38}$ The following spirochromanols $\mathbf{4 a -}$ 


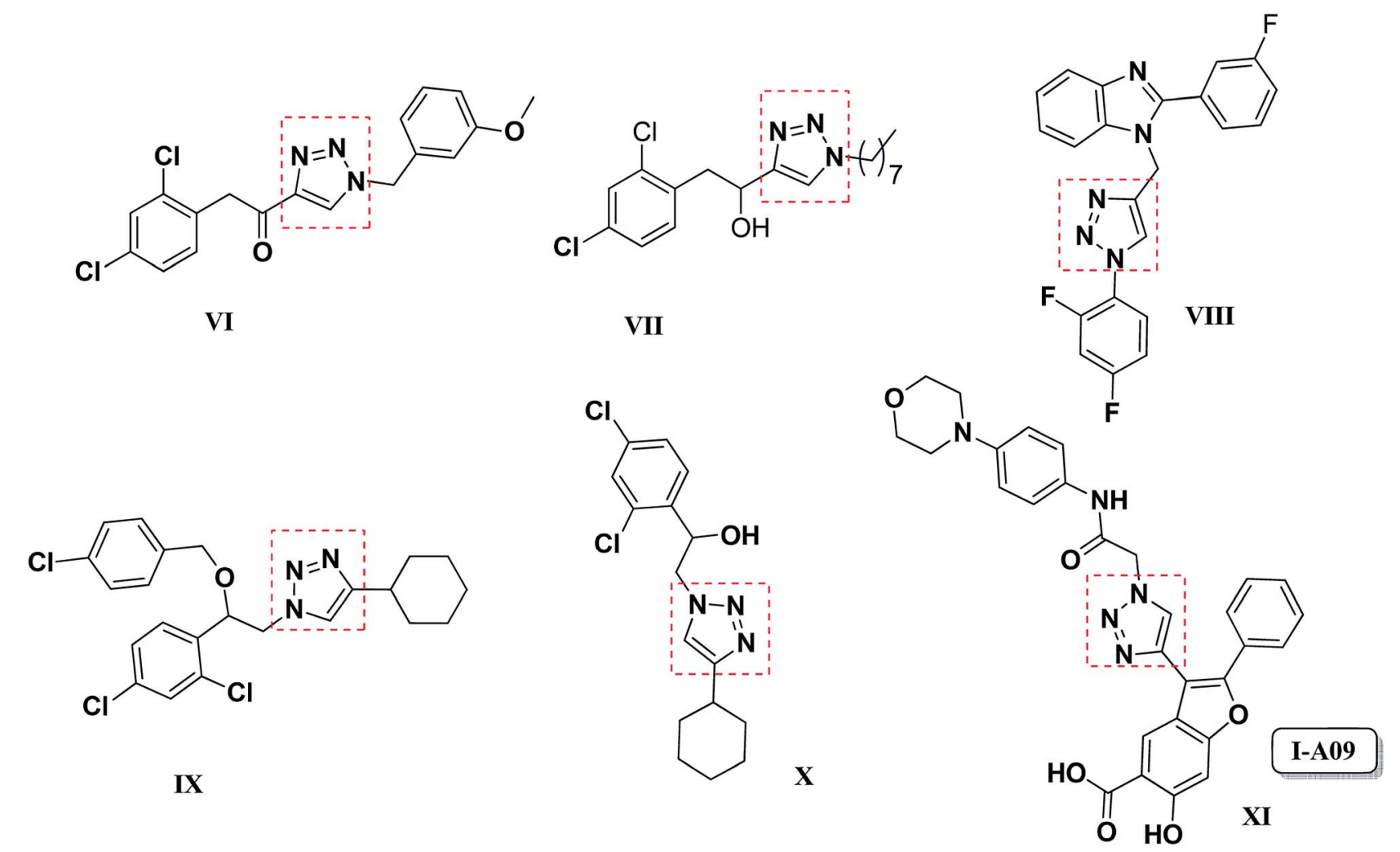

Fig. 2 1,2,3-Triazole based inhibitors reported as antimycobacterial agents.<smiles>c1ccc2c(c1)-c1nn[nH]c1-2</smiles><smiles>Cc1ccccc1-c1ccc(/C=C/C2c3[nH]nnc3C[C@H](C)C2C)nc1</smiles>

Fig. 3 Fused triazoles as potential drug candidates.

c on deprotection and dehydration with excess $6 \mathrm{~N} \mathrm{HCl}$ provided the corresponding spirochromene $\mathbf{5 a}-\mathbf{c} .^{39,40}$ Thus obtained spirochromenes $\mathbf{5 a - c}$ on $[3+2]$ Huisgen cycloaddition using a catalytic amount of pyrrolidine, with various aryl azides $\mathbf{6 a - e} \mathbf{e}^{\mathbf{4 1}}$ furnished 1,2,3-triazole-fused spirochromene scaffolds $7 \mathbf{a}-\mathbf{o}$ in low to moderate yields (Scheme $1 \&$ Fig. 5)..$^{42,43}$

The synthesized 1,2,3-triazole-fused spirochromene scaffolds were characterized by ${ }^{1} \mathrm{H}$ NMR, ${ }^{13} \mathrm{C}$ NMR, mass and FTIR spectral analysis; X-ray diffractometry confirmed the structure of compound 7a (CCDC 1820092†) $)^{44}$ as shown in Fig. 6.

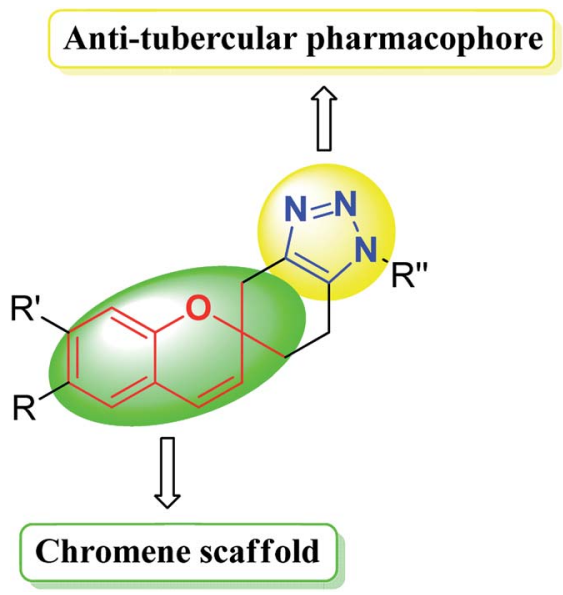

Fig. 4 Design of novel 1,2,3-triazole-fused spirochromenes as possible antimycobacterial agents.

\section{Anti-tubercular assay}

In vitro MTB screening. Our fifteen compound library was screened for in vitro anti-tubercular activity against Mycobacterium tuberculosis $\mathrm{H} 37 \mathrm{Rv}$ using Microplate Alamar Blue Assay (MABA) for the determination of MIC (the lowest concentration of an antimicrobial that will inhibit the visible growth of a bacteria after overnight incubation). ${ }^{45}$ Upon investigation of anti-tubercular activity data (Table 1), it was revealed that all the 

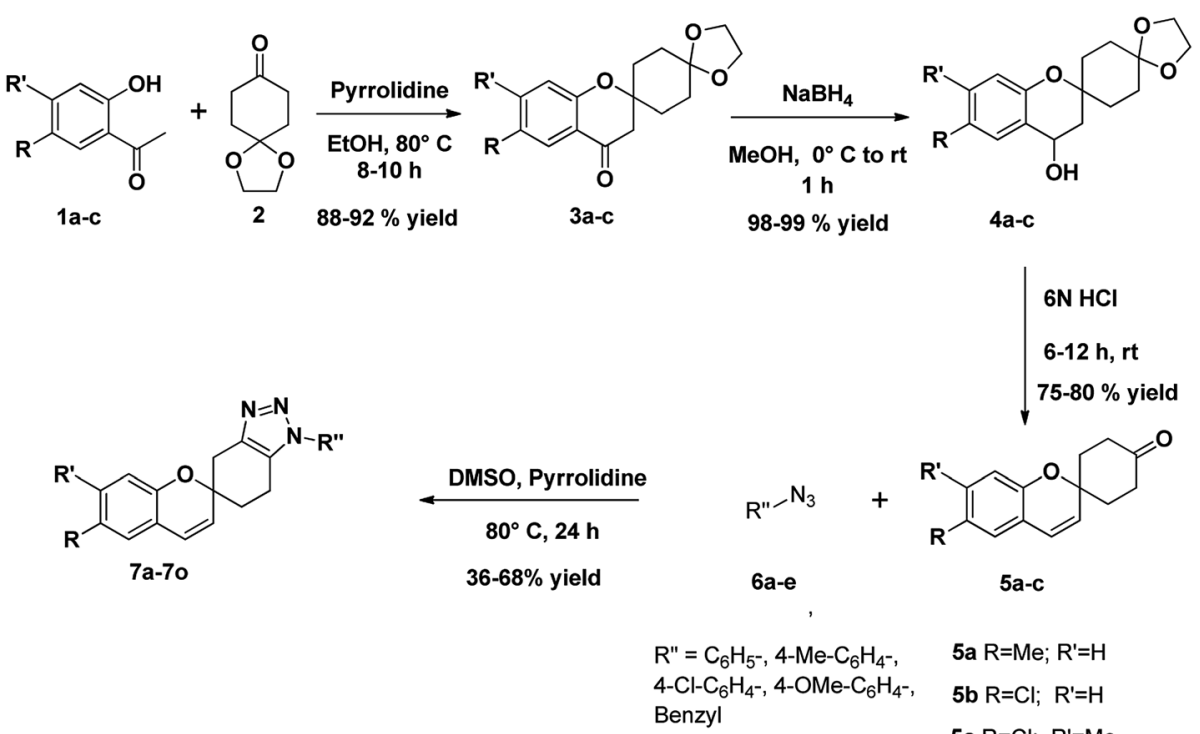

5a $\mathrm{R}=\mathrm{Me} ; \mathrm{R}^{\prime}=\mathrm{H}$

5b $\mathrm{R}=\mathrm{Cl} ; \mathrm{R}^{\prime}=\mathrm{H}$

5c $\mathrm{R}=\mathrm{Cl} ; \mathrm{R}^{\prime}=\mathrm{Me}$

Scheme 1 Synthesis of 1,2,3-triazole-fused spirochromenes.

synthesized 1,2,3-triazole-fused spirochromene scaffolds (7a-o) were found to possess moderate to high inhibitory activity.

As observed from Table 1, the tested compounds showed antimycobacterial activity with MIC values between 4.11 and $75.80 \mu \mathrm{M}$. Out of the various compounds tested, compounds $7 \mathbf{a}$, $\mathbf{7 c}, \mathbf{7 d}, \mathbf{7 f}, \mathbf{7 i}, 7 \mathbf{j}, 7 \mathbf{k}, \mathbf{7 m}$ and $\mathbf{7 n}$ with MIC values varying from 4.11 to $50.40 \mu \mathrm{M}$ possess more inhibitory efficiency compared to that of standard pyrazinamide ( $\mathrm{MIC}=50.77 \mu \mathrm{M}$ ). Compounds $7 \mathbf{a}, 7 \mathbf{d}$ and $7 \mathbf{i}$ were found to possess excellent potency i.e. 4.74 $\mu \mathrm{M}, 4.34 \mu \mathrm{M}$ and $4.11 \mu \mathrm{M}$ respectively, while compounds $7 \mathrm{k}(8.6$ $\mu \mathrm{M})$ and $7 \mathbf{m}(7.67 \mu \mathrm{M})$ were close as compared to first line antitubercular drug ethambutol $(\mathrm{MIC}=7.64 \mu \mathrm{M})$. However, all the compounds exhibited lower inhibitory efficiency compared to isoniazid $(\mathrm{MIC}=0.437 \mu \mathrm{M})$ and rifampicin $(\mathrm{MIC}=0.5 \mu \mathrm{M})$.

In vitro cytotoxicity screening. As a result, the compounds $\mathbf{7 a}, \mathbf{7 d}, \mathbf{7 f}, \mathbf{7 i}, \mathbf{7 k}, \mathbf{7 m}$ and $\mathbf{7 n}$ exhibited good in vitro antimycobacterial potency and were further evaluated for their toxicity in a RAW 264.7 cell line at a concentration of $50 \mu \mathrm{g} \mathrm{mL}$ using the 3-(4,5-dimethylthiazol-2-yl)-2,5-diphenyltetrazolium bromide (MTT) assay. ${ }^{46}$ The most promising anti-TB compounds $7 \mathbf{7 a}, 7 \mathbf{d}$ and $7 \mathbf{i}$ showed $30.23,33.14$ and $29.36 \%$ cytotoxicity, respectively.

\section{Experimental}

All the reagents and solvents were purchased from commercial sources. Reactions were monitored by thin layer chromatography (TLC) on silica gel plates $\left(60 \mathrm{~F}_{254}\right)$, visualization done by exposing to iodine vapour and ultraviolet light. Column chromatography was performed on silica gel (60-120 mesh) using distilled hexane, acetone. ${ }^{1} \mathrm{H}$ NMR $(400 \mathrm{MHz})$ and ${ }^{13} \mathrm{C}$ NMR $(100$ $\mathrm{MHz}$ ) spectra were recorded in $\mathrm{CDCl}_{3}$ or DMSO-d6 solvents by using Bruker Avance II 400 spectrometer. Proton chemical shifts $(\delta)$ are relative to tetramethylsilane (TMS, $\delta=0.00)$ as internal standard and expressed in ppm. Spin multiplicities are given as s (singlet), d (doublet), dd (doublet of doublet), td (triplet of doublet) and $\mathrm{m}$ (multiplet). Coupling constants $(J$ ) are given in hertz. Mass spectra were recorded on GCMS-QP 1000 EX mass spectrometer. Infrared spectra were recorded on a Shimadzu FT-IR-8400s spectrometer. Melting points were determined using melting point apparatus and are uncorrected.

\section{General procedure for the synthesis of compound (3a-c)}

To a solution of 1,4-dioxaspiro[4.5]decan-8-one (2) (156 mg, 1 mmol) in dry ethanol, a catalytic amount of pyrrolidine was added followed by a substituted $2^{\prime}$-hydroxyacetophenones (1ac) $(1 \mathrm{mmol})$. The reaction mixture was heated under reflux for $8-$ $10 \mathrm{~h}$ with constant stirring. The solvent was removed under reduced pressure and the residue was dissolved in ethyl acetate. The mixture was washed with a $1 \mathrm{M}$ aqueous solution of hydrochloric acid, with a $1 \mathrm{M}$ aqueous solution of sodium hydroxide and brine. The organic extracts were dried over sodium sulfate, filtered, and concentrated under reduced pressure. The resulting crude product was purified by column chromatography (eluent: PE/acetone mixtures of increasing polarity) to obtain the compounds 6,7-substituted dispiro [chromane-2,1'-cyclohexane-4' ${ }^{\prime} 2^{\prime \prime}$-[1,3]dioxolan]-4-ones (3a-c) as white solids.

\section{General procedure for the synthesis of compound (4a-c)}

To a stirred suspension of sodium borohydride $(37.83 \mathrm{mg}, 1$ $\mathrm{mmol}$ ) in $\mathrm{MeOH}$, a solution of 6,7-substituted dispiro[chromane-2,1'-cyclohexane- $4^{\prime}, 2^{\prime \prime}$-[1,3]dioxolan]-4-ones (3a-c) (1 $\mathrm{mmol}$ ) in $\mathrm{MeOH}$ was added drop wise at $0{ }^{\circ} \mathrm{C}$ through an addition funnel. The resulting mixture was allowed to stir at room temperature for $1 \mathrm{~h}$. The reaction mixture was concentrated in vacuo, poured into ice and saturated $\mathrm{NaHCO}_{3}$ aqueous solution and extracted with EtOAc. The combined organics were washed with brine, dried over anhydrous sodium sulfate, and 
<smiles>Cc1ccc2c(c1)C=CC1(CCc3c(nnn3-c3ccccc3)C1)O2</smiles>

$7 a, 45 \%$<smiles>Cc1ccc(-n2nnc3c2CCC2(C=Cc4cc(C)ccc4O2)C3)cc1</smiles>

$7 b, 57 \%$<smiles>Cc1ccc2c(c1)C=CC1(CCc3c(nnn3-c3ccc(Cl)cc3)C1)O2</smiles>

7c, $48 \%$<smiles>COc1ccc(-n2nnc3c2CCC2(C=Cc4cc(C)ccc4O2)C3)cc1</smiles>

$7 \mathrm{~d}, \mathbf{4 2} \%$<smiles>Cc1ccc2c(c1)C=CC1(CCc3c(nnn3Cc3ccccc3)C1)O2</smiles>

$7 e, 36 \%$<smiles>C[R5](C)(C)c1cc2c(cc1Cl)OC1(C=C2)CCc2c(nnn2-c2ccccc2)C1</smiles><smiles>Cc1ccc(-n2nnc3c2CCC2(C=Cc4cc(Cl)ccc4O2)C3)cc1</smiles>

$7 \mathrm{~g}, 60 \%$<smiles>Clc1ccc(-n2nnc3c2CCC2(C=Cc4cc(Cl)ccc4O2)C3)cc1</smiles>

$7 \mathrm{~h}, 54 \%$<smiles>COc1ccc(-n2nnc3c2CCC2(C=Cc4cc(Cl)ccc4O2)C3)cc1</smiles><smiles>COc1ccc(-n2nnc3c2CCC2(C=Cc4cc(Cl)c(C)cc4O2)C3)cc1</smiles><smiles>Cc1cc2c(cc1Cl)C=CC1(CCc3c(nnn3-c3ccc(Cl)cc3)C1)O2</smiles><smiles>CC(C)(C)c1cc(Cl)ccc1OC12C=Cc3c(nnn3Cc3ccccc3)C1CC2</smiles><smiles>Cc1cc2c(cc1Cl)C=CC1(CCc3c(nnn3Cc3ccccc3)C1)O2</smiles>

$70,42 \%$

Fig. 5 1,2,3-Triazole fused spirochromenes with isolated yields.

concentrated in vacuo to give 6,7-substituted dispiro[chromane$2,1^{\prime}$-cyclohexane- $4^{\prime}, 2^{\prime \prime}$-[1,3]dioxolan]-4-ols (4a-c) as white solids.

\section{General procedure for the synthesis of compound (5a-c)}

In a round bottom flask the previous spiro compounds $(\mathbf{4 a - c})$ dissolved in acetone was taken. To this solution excess amount of $6 \mathrm{~N} \mathrm{HCl}$ was added at room temperature. The reaction was allowed to stir at room temperature until the ketal has consumed totally (monitored by TLC). After completion of the reaction, the reaction mixture was slowly quenched with saturated aqueous $\mathrm{NaHCO}_{3}$ until pH 7 was reached. The solution was diluted with ethyl acetate. The phases were separated and the aqueous phase was back-extracted with ethyl acetate twice. The combined organic phases were washed with brine, dried over $\mathrm{Na}_{2} \mathrm{SO}_{4}$, filtered and concentrated under reduce pressure. The crude material was purified by flash chromatography (PE/ acetones as the eluents). The corresponding fractions were combined and concentrated under reduce pressure yielding 6,7- substituted spiro[chromene-2, $\mathbf{1}^{\prime}$-cyclohexan]-4'-ones (5a-c) as white solids.

\section{General procedure for the synthesis of compound (7a-o)}

The catalyst pyrrolidine $(0.1 \mathrm{mmol})$ was added to a solution of aryl azides $6 \mathbf{a}-\mathbf{e}(0.5 \mathrm{mmol})$ and compound $5 \mathbf{a}-\mathbf{c}(1 \mathrm{mmol})$ in DMSO and the reaction mixture was stirred at $80{ }^{\circ} \mathrm{C}$ for $24 \mathrm{~h}$. The completion of the reaction was confirmed by TLC (PE/ EtOAc $5: 2$ ). The crude product was purified by column chromatography on silica gel, eluting with PE/acetone $(10: 1$ to $4: 1$ ), to afford the desired products $7 \mathbf{a}-\mathbf{o}$ as white solids.

\section{Antimycobacterial activity}

In vitro MTB MABA assay. Briefly, the inoculum was prepared from fresh LJ medium re-suspended in 7H9-S medium (7H9 broth, $0.1 \%$ casitone, $0.5 \%$ glycerol, supplemented oleic acid, albumin, dextrose, and catalase [OADC]), adjusted to a McFarland 


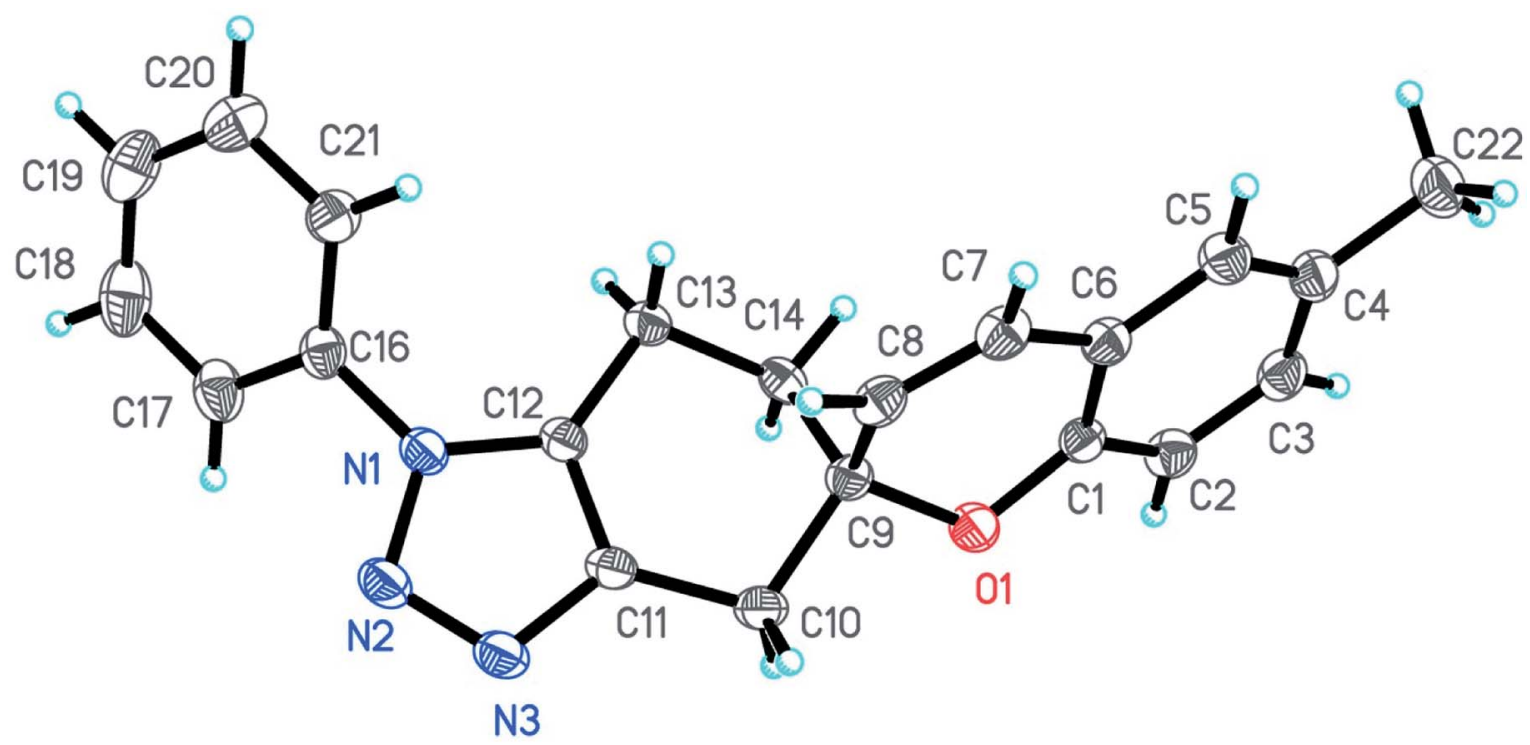

Fig. 6 A view of KA357, showing the atom-labelling scheme of compound 7a. Displacement ellipsoids are drawn at the 30\% probability level and $\mathrm{H}$ atoms are represented by circles of arbitrary radii.

Table 1 Anti-tubercular and toxicity evaluation of 7a-o against $M$. tuberculosis $\mathrm{H}_{37 \mathrm{Rv}^{a}}$

\begin{tabular}{|c|c|c|c|}
\hline Compounds & $\begin{array}{l}\text { MIC } \\
\left.(\mu \mathrm{g} \mathrm{mL})^{-1}\right)\end{array}$ & $\begin{array}{l}\text { MIC } \\
(\mu \mathrm{M})\end{array}$ & $\begin{array}{l}\text { Cytotoxicity in } \% \\
\text { inhibition at } 50 \mu \mathrm{gL}^{-1}\end{array}$ \\
\hline $7 a^{*}$ & 1.56 & 4.74 & 30.23 \\
\hline $7 \mathbf{b}$ & $>25$ & 75.80 & ND \\
\hline $7 c$ & 12.5 & 34.43 & ND \\
\hline $7 d^{*}$ & 1.56 & 4.34 & 33.14 \\
\hline $7 e$ & $>25$ & 75.80 & ND \\
\hline $7 f$ & 6.25 & 17.90 & 21.41 \\
\hline $7 \mathrm{~g}$ & 25 & 68.87 & ND \\
\hline $7 \mathrm{~h}$ & 25 & 65.27 & ND \\
\hline $7 i^{*}$ & 1.56 & 4.11 & 29.36 \\
\hline $7 \mathbf{j}$ & 12.5 & 34.43 & ND \\
\hline $7 \mathbf{k}^{*}$ & 3.125 & 8.60 & 24.90 \\
\hline 71 & $>25$ & 68.96 & ND \\
\hline $7 \mathbf{m}^{*}$ & 3.125 & 7.87 & 24.76 \\
\hline $7 n$ & 6.25 & 15.90 & 22.64 \\
\hline 70 & 25 & 66.31 & ND \\
\hline Isoniazid & 0.055 & 0.437 & ND \\
\hline Rifampicin & 0.411 & 0.50 & ND \\
\hline Ethambutol & 1.56 & 7.64 & ND \\
\hline
\end{tabular}

$a *$ Represent more active compounds; MIC: minimum inhibitory concentration (the lowest concentration that inhibited the bacterial growth). MIC values are interpreted as an average of duplicates. ND = not determined.

tube no. 1 , and diluted $1: 20 ; 100 \mu \mathrm{L}$ was used as inoculum. Each drug stock solution was thawed and diluted in 7H9-S at four-fold the final highest concentration tested. Serial two-fold dilutions of each drug were prepared directly in a sterile 96-well microtiter plate using $100 \mu \mathrm{L}$ 7H9-S. A growth control containing no antibiotic and a sterile control were also prepared on each plate. Sterile water was added to all perimetre wells to avoid evaporation during the incubation. The plate was covered, sealed in plastic bags and incubated at $37^{\circ} \mathrm{C}$ in normal atmosphere. After 7 days incubation, $30 \mu \mathrm{L}$ of alamar blue solution was added to each well, and the plate was re-incubated overnight. A change in colour from blue (oxidised state) to pink (reduced) indicated the growth of bacteria, and the MIC was defined as the lowest concentration of drug that prevented this change in colour. ${ }^{45}$

*Standards INH \& amp; RIF (0.437 \& amp; $0.5 \mu \mathrm{M})$.

In vitro cytotoxicity screening. The in vitro cytotoxicity of the privileged anti-tubercular active analogues with lower MIC value were assessed by 3-(4,5-dimethylthiazol-2-yl)-2,5diphenyltetrazolium bromide (MTT) assay against growth inhibition of RAW 264.7 cells (obtained from National Centre for Cell Science, Pune) at $50 \mu \mathrm{g} \mathrm{mL}{ }^{-1}$ concentration. ${ }^{29}$ Cell lines were maintained at $37{ }^{\circ} \mathrm{C}$ in a humidified $5 \% \mathrm{CO}_{2}$ incubator (Thermo Scientific). Detached the adhered cells and followed by centrifugation to get cell pellet. Fresh media was added to the pellet to make a cell count using haemocytometer and plate 100 $\mu \mathrm{L}$ of media with cells ranging from 5000-6000 per well in a 96well plate. The plate was incubated overnight in $\mathrm{CO}_{2}$ incubator for the cells to adhere and regain its shape. After $24 \mathrm{~h}$ cells were treated with the test compounds at $25 \mu \mathrm{M}$ diluted using the media to deduce the percentage inhibition on human normal cells. The cells were incubated for $48 \mathrm{~h}$ to assay the effect of the test compounds on different cell lines. Zero hour reading was noted down with untreated cells and also control with $1 \%$ DMSO to subtract further from the $48 \mathrm{~h}$ reading. After $48 \mathrm{~h}$ incubation, cells were treated by MTT ((4,5-dimethylthiazol-2yl)-2,5-diphenyltetrazolium bromide) dissolved in PBS (5 mg $\mathrm{mL}^{-1}$ ) and incubated for $3-4 \mathrm{~h}$ at $37^{\circ} \mathrm{C}$. The formazan crystals thus formed were dissolved in $100 \mu \mathrm{L}$ of DMSO and the viability was measured at $540 \mathrm{~nm}$ on a multimode reader (Spectra max). The values were further calculated for percentage inhibition which in turn helps us to know the cytotoxicity of the test compounds. ${ }^{46}$ 


\section{Crystallographic data}

X-ray data for the compound 7a (KA357) was collected at room temperature on a Bruker D8 QUEST instrument with an I $\mu$ S Mo microsource $(\lambda=0.7107 \AA)$ and a PHOTON-100 detector. The raw data frames were reduced and corrected for absorption effects using the Bruker Apex 3 software suite programs. ${ }^{47}$ The structure was solved using intrinsic phasing method ${ }^{47}$ and further refined with the SHELXL ${ }^{48}$ program and expanded using Fourier techniques. Anisotropic displacement parameters were included for all non-hydrogen atoms. All $\mathrm{C}$ bound $\mathrm{H}$ atoms were positioned geometrically and treated as riding on their parent $\mathrm{C}$ atoms $\left[\mathrm{C}-\mathrm{H}=0.93-0.97 \AA\right.$, and $U_{\text {iso }}(\mathrm{H})=1.5 U_{\text {eq. }}(\mathrm{C})$ for methyl $\mathrm{H}$ or $1.2 U_{\text {eq. }}(\mathrm{C})$ for other $\mathrm{H}$ atoms].

Crystal data for KA357. $\mathrm{C}_{21} \mathrm{H}_{19} \mathrm{~N}_{3} \mathrm{O}\left(M=329.40 \mathrm{~g} \mathrm{~mol}^{-1}\right)$ : monoclinic, space group $P 2_{1} / n$ (no. 14), $a=12.29074(14) \AA$, $b=$ 6.54998(8) $\mathrm{A}, c=21.8593(3) \AA, \beta=106.2989(5)^{\circ}, V=1689.04(4)$ $\AA^{3}, Z=4, T=294.15 \mathrm{~K}, \mu($ Mo K $\alpha)=0.082 \mathrm{~mm}^{-1}, D_{\text {calc }}=$ $1.2953 \mathrm{~g} \mathrm{~cm}^{-3}, 23247$ reflections measured $\left(4.42^{\circ} \leq 2 \Theta \leq\right.$ $\left.61.14^{\circ}\right), 5166$ unique $\left(R_{\text {int }}=0.0288, R_{\text {sigma }}=0.0248\right)$ which were used in all calculations. The final $R_{1}$ was $0.0560(I>2 \sigma(I))$ and $\mathrm{w} R_{2}$ was 0.1638 (all data). CCDC 1820092 contains supplementary crystallographic data for the structure. $\dagger$

6-Methyldispiro[chroman-2,1'-cyclohexane- $4^{\prime}, 2^{\prime \prime}$-[1,3]dioxolan]4-one (3a). White solid; yield: $92 \%$; mp $74-76{ }^{\circ} \mathrm{C} ; R_{\mathrm{f}}=0.37(\mathrm{PE} /$ EtOAc 5 : 1). IR (KBr): 2932, 2891, 1689, 1616, 1484 1285, 1136, $1090 \mathrm{~cm}^{-1} .{ }^{1} \mathrm{H}$ NMR $\left(400 \mathrm{MHz}, \mathrm{CDCl}_{3}\right): \delta=7.65(\mathrm{~d}, J=2.0 \mathrm{~Hz}, 1 \mathrm{H})$, $7.32-7.28(\mathrm{~d}, J=8.5,2.0 \mathrm{~Hz}, 1 \mathrm{H}), 6.88(\mathrm{~d}, J=8.5 \mathrm{~Hz}, 1 \mathrm{H}), 4.01-3.92$ $(\mathrm{m}, 4 \mathrm{H}), 2.69(\mathrm{~s}, 2 \mathrm{H}), 2.30(\mathrm{~s}, 3 \mathrm{H}), 2.15-2.07(\mathrm{~m}, 2 \mathrm{H}), 1.98(\mathrm{td}, J=$ 13.1, $4.3 \mathrm{~Hz}, 2 \mathrm{H}), 1.72(\mathrm{td}, J=13.1,4.3 \mathrm{~Hz}, 2 \mathrm{H}), 1.63-1.56(\mathrm{~m}, 2 \mathrm{H})$. ${ }^{13} \mathrm{C}$ NMR $\left(100 \mathrm{MHz}, \mathrm{CDCl}_{3}\right): \delta=192.5,157.3,137.3,130.4,126.2$, 120.4, 118.1, 108.0, 78.5, 64.4, 64.3, 48.0, 32.1, 30.0, 20.4. MS (ESI) $m / z(\%)=289(100)[\mathrm{M}+\mathrm{H}]^{+}$. Anal. calcd for $\mathrm{C}_{17} \mathrm{H}_{20} \mathrm{O}_{4}: \mathrm{C}, 70.81 ; \mathrm{H}$, 6.99. Found: C, 70.83; H, 6.97.

6-Chlorodispiro[chroman-2,1'-cyclohexane-4', $2^{\prime \prime}$-[1,3]dioxolan]4-one (3b). White solid; yield: $88 \%$; mp 98-100 ${ }^{\circ} \mathrm{C} ; R_{\mathrm{f}}=0.34(\mathrm{PE} /$ EtOAc 5 : 1). IR (KBr): 2947, 2884, 1686, 1602, 1467, 1259, 1150, $1091 \mathrm{~cm}^{-1} .{ }^{1} \mathrm{H}$ NMR $\left(400 \mathrm{MHz}, \mathrm{CDCl}_{3}\right): \delta=7.82(\mathrm{~d}, J=2.7 \mathrm{~Hz}, 1 \mathrm{H})$, $7.42(\mathrm{dd}, J=8.8,2.7 \mathrm{~Hz}, 1 \mathrm{H}), 6.94(\mathrm{~d}, J=8.8 \mathrm{~Hz}, 1 \mathrm{H}), 4.01-3.92(\mathrm{~m}$, $4 \mathrm{H}), 2.71(\mathrm{~s}, 2 \mathrm{H}), 2.15-2.06(\mathrm{~m}, 2 \mathrm{H}), 1.96(\mathrm{td}, J=13.1,4.2 \mathrm{~Hz}, 2 \mathrm{H})$, $1.74(\mathrm{td}, J=13.1,4.2 \mathrm{~Hz}, 2 \mathrm{H}), 1.63-1.62(\mathrm{~m}, 1 \mathrm{H}), 1.60-1.59(\mathrm{~m}, 1 \mathrm{H})$. ${ }^{13} \mathrm{C} \mathrm{NMR}\left(100 \mathrm{MHz}, \mathrm{CDCl}_{3}\right): \delta=191.1,157.8,136.1,126.5,126.0$, $121.5,120.0,107.8,79.2,64.5,64.3,47.6,32.1,29.9$. MS (ESI) $m / z$ $(\%)=309(100)[\mathrm{M}+\mathrm{H}]^{+}$. Anal. calcd for $\mathrm{C}_{16} \mathrm{H}_{17} \mathrm{ClO}_{4}$ : C, 62.24; $\mathrm{H}$, 5.55. Found: C, 62.28; H, 5.51 .

6-Chloro-7-methyldispiro[chromane-2,1'-cyclohexane- $\mathbf{4}^{\prime}, \mathbf{2}^{\prime \prime}$ [1,3]dioxolan]-4-one (3c). White solid; yield: 89\%; mp 99-100 ${ }^{\circ} \mathrm{C}$; $R_{\mathrm{f}}=0.34$ (PE/EtOAc $\left.5: 1\right)$. IR (KBr): 2926, 2883, 1685, 1606, 1443, 1251, 1168, $1086 \mathrm{~cm}^{-1} .{ }^{1} \mathrm{H}$ NMR (400 MHz, $\left.\mathrm{CDCl}_{3}\right): \delta=$ $7.81(\mathrm{~s}, 1 \mathrm{H}), 6.88(\mathrm{~s}, 1 \mathrm{H}), 4.01-3.91(\mathrm{~m}, 4 \mathrm{H}), 2.68(\mathrm{~s}, 2 \mathrm{H}), 2.37(\mathrm{~s}$, $3 \mathrm{H}), 2.10(\mathrm{dd}, J=15.7,2.4 \mathrm{~Hz}, 2 \mathrm{H}), 1.96(\mathrm{td}, J=13.1,4.2 \mathrm{~Hz}, 2 \mathrm{H})$, $1.73(\mathrm{td}, J=13.1,4.2 \mathrm{~Hz}, 2 \mathrm{H}), 1.64-1.60(\mathrm{~m}, 1 \mathrm{H}), 1.58-1.55(\mathrm{~m}$, 1H). ${ }^{13} \mathrm{C} \mathrm{NMR}\left(100 \mathrm{MHz}, \mathrm{CDCl}_{3}\right): \delta=190.9,157.6,145.2,127.2$, 126.3, 120.5, 119.8, 107.9, 79.1, 64.5, 64.3, 47.6, 32.1, 29.9, 20.8. MS (ESI) $m / z(\%)=323(100)[\mathrm{M}+\mathrm{H}]^{+}$. Anal. calcd for $\mathrm{C}_{17} \mathrm{H}_{19} \mathrm{ClO}_{4}$ : C, 63.26; H, 5.93. Found: C, 63.28; H, 5.91.
6-Methyldispiro[chromane-2,1'-cyclohexane-4' $\mathbf{2}^{\prime}$ ' $-[1,3]$ dioxolan]4-ol (4a). White solid; yield: 99\%; $\mathrm{mp} 70-72{ }^{\circ} \mathrm{C} ; R_{\mathrm{f}}=0.20$ (PE/EtOAc 5 : 1). IR (KBr): 3253, 2930, 2858, 1612, 1441, 1248, 1140, $1090 \mathrm{~cm}^{-1} .{ }^{1} \mathrm{H}$ NMR (400 MHz, DMSO-d6): $\delta=7.20$ (d, $J=2.0 \mathrm{~Hz}$, $1 \mathrm{H}), 6.91(\mathrm{dd}, J=8.3,2.0 \mathrm{~Hz}, 1 \mathrm{H}), 6.63(\mathrm{~d}, J=8.3 \mathrm{~Hz}, 1 \mathrm{H}), 5.27$ (d, $J$ $=6.3 \mathrm{~Hz}, 1 \mathrm{H}), 4.67-4.58(\mathrm{~m}, 1 \mathrm{H}), 3.92-3.81(\mathrm{~m}, 4 \mathrm{H}), 2.21(\mathrm{~s}, 3 \mathrm{H})$, $2.02(\mathrm{dd}, J=13.4,6.3 \mathrm{~Hz}, 1 \mathrm{H}), 1.89-1.44(\mathrm{~m}, 9 \mathrm{H}) .{ }^{13} \mathrm{C}$ NMR $(100$ $\left.\mathrm{MHz}, \mathrm{CDCl}_{3}\right): \delta=150.5,130.1,129.8,128.0,124.4,117.2,108.6$, 74.4, 64.3, 64.2, 63.5, 41.9, 34.2, 31.4, 30.0, 20.6. MS (ESI) $\mathrm{m} / \mathrm{z}(\%)=$ $313(100)[\mathrm{M}+\mathrm{Na}]^{+}$. Anal. calcd for $\mathrm{C}_{17} \mathrm{H}_{22} \mathrm{O}_{4}$ : C, 70.32; H, 7.64. Found: C, 70.35; H, 7.61.

6-Chlorodispiro[chromane-2,1'-cyclohexane-4' $\mathbf{2}^{\prime \prime}$-[1,3]dioxolan]4-ol (4b). White solid; yield: 98\%; mp 90-92 ${ }^{\circ} \mathrm{C} ; R_{\mathrm{f}}=0.28$ (PE/EtOAc 5 : 1). IR (KBr): 3254, 2934, 2886, 1608, 1475, 1241, 1173, $1092 \mathrm{~cm}^{-1}$. ${ }^{1} \mathrm{H}$ NMR (400 MHz, DMSO-d6): $\delta=7.39$ (d, $J=2.7 \mathrm{~Hz}$, $1 \mathrm{H}), 7.15(\mathrm{dd}, J=8.7,2.7 \mathrm{~Hz}, 1 \mathrm{H}), 6.79(\mathrm{~d}, J=8.7 \mathrm{~Hz}, 1 \mathrm{H}), 5.50$ (d, $J$ $=6.2 \mathrm{~Hz}, 1 \mathrm{H}), 4.62-4.70(\mathrm{~m}, 1 \mathrm{H}), 3.92-3.81(\mathrm{~m}, 4 \mathrm{H}), 2.06(\mathrm{dd}, J=$ 13.5, $6.3 \mathrm{~Hz}, 1 \mathrm{H}), 1.89-1.45$ (m, 9H). ${ }^{13} \mathrm{C} \mathrm{NMR}$ (100 MHz, $\mathrm{CDCl}_{3}$ ): $\delta=151.4,129.3,127.6,126.2,125.3,118.7,108.4,75.2,64.4,64.3$, 63.1, 41.5, 34.3, 31.3, 30.0. MS (ESI) $m / z(\%)=333(100)[\mathrm{M}+\mathrm{Na}]^{+}$. Anal. calcd for $\mathrm{C}_{16} \mathrm{H}_{19} \mathrm{ClO}_{4}$ : C, 61.84; H, 6.16. Found: C, 61.89; H, 6.11.

6-Chloro-7-methyldispiro[chromane-2,1'-cyclohexane-4', $\mathbf{2}^{\prime \prime}$-[1,3] dioxolan]-4-ol (4c). White solid; yield: $99 \%$; mp 56-58 ${ }^{\circ} \mathrm{C} ; R_{\mathrm{f}}=0.22$ (PE/EtOAc 5 : 1). IR (KBr): 3254, 2928, 2861, 1616, 1444, 1252, 1168, $1091 \mathrm{~cm}^{-1} .{ }^{1} \mathrm{H}$ NMR (400 MHz, DMSO-d6): $\delta=7.36$ (s, 1H), 6.77 (s, $1 \mathrm{H}), 5.43(\mathrm{~d}, J=6.1 \mathrm{~Hz}, 1 \mathrm{H}), 4.67-4.59(\mathrm{~m}, 1 \mathrm{H}), 3.90-3.84(\mathrm{~m}, 4 \mathrm{H})$, $2.23(\mathrm{~s}, 3 \mathrm{H}), 2.04$ (dd, $J=13.5,6.2 \mathrm{~Hz}, 1 \mathrm{H}), 1.90-1.45(\mathrm{~m}, 9 \mathrm{H}) .{ }^{13} \mathrm{C}$ $\operatorname{NMR}\left(100 \mathrm{MHz}, \mathrm{CDCl}_{3}\right): \delta=151.2,137.2,127.9,125.7,123.8,119.4$, 108.4, 75.0, 64.4, 64.3, 63.0, 41.7, 34.2, 31.3, 30.0, 19.9. MS (ESI) $m / z$ $(\%)=347(100)[\mathrm{M}+\mathrm{Na}]^{+}$. Anal. calcd for $\mathrm{C}_{17} \mathrm{H}_{21} \mathrm{ClO}_{4}: \mathrm{C}, 62.86 ; \mathrm{H}$, 6.52. Found: C, 62.84; $\mathrm{H}, 6.54$.

6-Methylspiro[chromene-2,1'-cyclohexan]-4'-one (5a). White solid; yield: $80 \%$; mp $72-74{ }^{\circ} \mathrm{C} ; R_{\mathrm{f}}=0.57$ (PE/EtOAc $5: 1$ ). IR (KBr): 3024, 2938, 2868, 1716, 1635, 1485, 1241, $1138 \mathrm{~cm}^{-1} \cdot{ }^{1} \mathrm{H}$ NMR (400 MHz, $\left.\mathrm{CDCl}_{3}\right): \delta=6.97(\mathrm{dd}, J=8.1,1.7 \mathrm{~Hz}, 1 \mathrm{H}), 6.85$ $(\mathrm{d}, J=1.7 \mathrm{~Hz}, 1 \mathrm{H}), 6.78(\mathrm{~d}, J=8.1 \mathrm{~Hz}, 1 \mathrm{H}), 6.42(\mathrm{~d}, J=9.7 \mathrm{~Hz}$, $1 \mathrm{H}), 5.58(\mathrm{~d}, J=9.7 \mathrm{~Hz}, 1 \mathrm{H}), 2.90(\mathrm{td}, J=14.3,6.3 \mathrm{~Hz}, 2 \mathrm{H}), 2.47-$ $2.36(\mathrm{~m}, 2 \mathrm{H}), 2.32-2.28(\mathrm{~m}, 1 \mathrm{H}), 2.27(\mathrm{~s}, 3 \mathrm{H}), 2.28-2.24(\mathrm{~m}, 1 \mathrm{H})$, $1.85(\mathrm{td}, J=13.8,5.1 \mathrm{~Hz}, 2 \mathrm{H}) .{ }^{13} \mathrm{C} \mathrm{NMR}\left(100 \mathrm{MHz}, \mathrm{CDCl}_{3}\right): \delta=$ 210.8, 149.9, 130.8, 129.8, 128.5, 127.1, 124.4, 121.6, 116.1, 74.8, $36.5,35.3,20.5$. MS (ESI) $m / z(\%)=229(100)[\mathrm{M}+\mathrm{H}]^{+}$. Anal. calcd for $\mathrm{C}_{15} \mathrm{H}_{16} \mathrm{O}_{2}$ : C, 78.92; H, 7.06; found: C, 78.97; H, 7.01.

6-Chlorospiro[chromene-2,1'-cyclohexan]-4'-one (5b). White solid; yield: $75 \%$; mp $58-60{ }^{\circ} \mathrm{C} ; R_{\mathrm{f}}=0.42$ (PE/EtOAc 5 : 1). IR (KBr): 2944, 2863, 1708, 1630, 1475, 1246, $1199 \mathrm{~cm}^{-1} .{ }^{1} \mathrm{H}$ NMR $\left(400 \mathrm{MHz}, \mathrm{CDCl}_{3}\right): \delta=7.11(\mathrm{dd}, J=8.5,2.5 \mathrm{~Hz}, 1 \mathrm{H}), 7.01(\mathrm{~d}, J=$ $2.5 \mathrm{~Hz}, 1 \mathrm{H}), 6.81(\mathrm{~d}, J=8.5 \mathrm{~Hz}, 1 \mathrm{H}), 6.39(\mathrm{~d}, J=9.8 \mathrm{~Hz}, 1 \mathrm{H}), 5.65$ $(\mathrm{d}, J=9.8 \mathrm{~Hz}, 1 \mathrm{H}), 2.81(\mathrm{td}, J=14.2,6.3 \mathrm{~Hz}, 2 \mathrm{H}), 2.47-2.36(\mathrm{~m}$, $2 \mathrm{H}), 2.34-2.25(\mathrm{~m}, 2 \mathrm{H}), 1.87(\mathrm{td}, J=13.8,5.1 \mathrm{~Hz}, 2 \mathrm{H}) .{ }^{13} \mathrm{C} \mathrm{NMR}$ $\left(100 \mathrm{MHz}, \mathrm{CDCl}_{3}\right): \delta=210.2,150.6,129.7,129.0,126.3,123.4$, 123.1, 117.7, 75.4, 36.4, 35.3. MS (ESI) $m / z(\%)=249(100)[\mathrm{M}+$ $\mathrm{H}]^{+}$. Anal. calcd for $\mathrm{C}_{14} \mathrm{H}_{13} \mathrm{ClO}_{2}$ : C, 67.61; H, 5.27. Found: C, $67.64 ; \mathrm{H}, 5.24$.

6-Chloro-7-methylspiro[chromene-2,1'-cyclohexan]-4'-one (5c). White solid; yield: $78 \% ; \operatorname{mp~} 68-70{ }^{\circ} \mathrm{C} ; R_{\mathrm{f}}=0.51(\mathrm{PE} / \mathrm{EtOAc}$ 
5 : 1). IR (KBr): 3021, 2925, 2858, 1720, 1634, 1486, 1226, $1147 \mathrm{~cm}^{-1} .{ }^{1} \mathrm{H}$ NMR $\left(400 \mathrm{MHz}, \mathrm{CDCl}_{3}\right): \delta=7.01(\mathrm{~s}, 1 \mathrm{H}), 6.77(\mathrm{~s}$, $1 \mathrm{H}), 6.38(\mathrm{~d}, J=9.8 \mathrm{~Hz}, 1 \mathrm{H}), 5.59(\mathrm{~d}, J=9.8 \mathrm{~Hz}, 1 \mathrm{H}), 2.81(\mathrm{td}, J=$ $14.2,6.3 \mathrm{~Hz}, 2 \mathrm{H}), 2.44-2.36(\mathrm{~m}, 2 \mathrm{H}), 2.32(\mathrm{~s}, 3 \mathrm{H}), 2.31-2.25(\mathrm{~m}$, $2 \mathrm{H}), 1.86(\mathrm{td}, J=13.8,5.1 \mathrm{~Hz}, 2 \mathrm{H}) .{ }^{13} \mathrm{C} \mathrm{NMR}\left(100 \mathrm{MHz}, \mathrm{CDCl}_{3}\right)$ : $\delta=210.5,150.5,137.1,128.7,126.5,126.4,123.2$, 120.9, 118.7, 75.2, 36.4, 35.3, 20.1. MS (ESI) $m / z(\%)=262(100)[\mathrm{M}+\mathrm{H}]^{+}$. Anal. calcd for $\mathrm{C}_{15} \mathrm{H}_{15} \mathrm{ClO}_{2}: \mathrm{C}, 68.57 ; \mathrm{H}, 5.75$. Found: $\mathrm{C}, 68.54 ; \mathrm{H}$, 5.78 .

$6^{\prime}$-Methyl-1-phenyl-1,4,6,7-tetrahydrospiro[benzo[d][1,2,3]triazole-5,2'-chromene] (7a). White solid; yield: 45\%; mp 126$128{ }^{\circ} \mathrm{C} ; R_{\mathrm{f}}=0.31$ (PE/EtOAc $\left.5: 2\right)$. IR (KBr): 3021, 2925, 2858, 1634, 1486, 1226, $1147 \mathrm{~cm}^{-1}$. ${ }^{1} \mathrm{H}$ NMR (400 MHz, $\left.\mathrm{CDCl}_{3}\right): \delta=$ 7.65-7.44 (m, 5H), $6.92(\mathrm{dd}, J=8.1,1.7 \mathrm{~Hz}, 1 \mathrm{H}), 6.86(\mathrm{~d}, J=$ $1.7 \mathrm{~Hz}, 1 \mathrm{H}), 6.66(\mathrm{~d}, J=8.1 \mathrm{~Hz}, 1 \mathrm{H}), 6.47$ (d, $J=9.7 \mathrm{~Hz}, 1 \mathrm{H}), 5.69$ (d, $J=9.7 \mathrm{~Hz}, 1 \mathrm{H}), 3.42(\mathrm{~d}, J=16.3 \mathrm{~Hz}, 1 \mathrm{H}), 3.08-2.92(\mathrm{~m}, 2 \mathrm{H})$, 2.81-2.73 (m, 1H), 2.39-2.30 (m, 1H), 2.26 (s, 3H), 1.97-1.86 (m, 1H). ${ }^{13} \mathrm{C} \mathrm{NMR}\left(100 \mathrm{MHz}, \mathrm{CDCl}_{3}\right): \delta=149.9,141.7,136.9,130.9$, $130.7,129.9$, 129.5, 128.7, 128.1, 127.1, 124.6, 123.0, 121.2, 116.3, 75.9, 33.6, 32.3, 20.5, 18.0. MS (ESI) $m / z(\%)=330(100)$ $[\mathrm{M}+\mathrm{H}]^{+}$. Anal. calcd for $\mathrm{C}_{21} \mathrm{H}_{19} \mathrm{~N}_{3} \mathrm{O}: \mathrm{C}, 76.57 ; \mathrm{H}, 5.81 ; \mathrm{N}, 12.76$. Found: C, 76.61; H, 5.82; N, 12.71.

6'-Methyl-1-(p-tolyl)-1,4,6,7-tetrahydrospiro[benzo[d][1,2,3]triazole-5,2'-chromene] (7b). White solid; yield: 57\%; mp 162$164{ }^{\circ} \mathrm{C} ; R_{\mathrm{f}}=0.34$ (PE/EtOAc $\left.5: 2\right)$. IR (KBr): 3036, 2923, 2855, 1645, 1491, 1225, $1150 \mathrm{~cm}^{-1} .{ }^{1} \mathrm{H}$ NMR (400 MHz, $\left.\mathrm{CDCl}_{3}\right): \delta=$ $7.48(\mathrm{~d}, J=8.2 \mathrm{~Hz}, 2 \mathrm{H}), 7.33(\mathrm{~d}, J=8.2 \mathrm{~Hz}, 2 \mathrm{H}), 6.91(\mathrm{~d}, J=$ $8.1 \mathrm{~Hz}, 1 \mathrm{H}), 6.85(\mathrm{~s}, 1 \mathrm{H}), 6.65(\mathrm{~d}, J=8.1 \mathrm{~Hz}, 1 \mathrm{H}), 6.46(\mathrm{~d}, J=$ $9.7 \mathrm{~Hz}, 1 \mathrm{H}), 5.68$ (d, $J=9.7 \mathrm{~Hz}, 1 \mathrm{H}), 3.40(\mathrm{~d}, J=16.5 \mathrm{~Hz}, 1 \mathrm{H})$, 3.04-2.90 (m, 2H), 2.78-2.68 (m, 1H), 2.44 (s, 3H), 2.37-2.28 (m, 1H), 2.26 (s, 3H), 1.96-1.86 (m, 1H). $\left.{ }^{13} \mathrm{C} \mathrm{NMR} \mathrm{(100} \mathrm{MHz,} \mathrm{CDCl}_{3}\right)$ : $\delta=149.9,141.5,138.8,134.4,130.9,130.6,130.1$, 129.9, 128.1, 127.1, 124.5, 122.9, 121.2, 116.3, 75.9, 33.6, 32.2, 21.2, 20.5, 17.9. MS (ESI) $m / z(\%)=344.30(100)[\mathrm{M}+\mathrm{H}]^{+}$. Anal. calcd for $\mathrm{C}_{22} \mathrm{H}_{21} \mathrm{~N}_{3} \mathrm{O}: \mathrm{C}, 76.94 ; \mathrm{H}, 6.16 ; \mathrm{N}, 12.24$. Found: C, 76.98; H, $6.15 ; \mathrm{N}, 12.27$.

1-(4-Chlorophenyl)-6'-methyl-1,4,6,7-tetrahydrospiro[benzo $[d]$ [1,2,3]triazole-5,2'-chromene] (7c). White solid; yield: $48 \%$; mp $122-124{ }^{\circ} \mathrm{C} ; R_{\mathrm{f}}=0.40$ (PE/EtOAc $5: 2$ ). IR (KBr): 3031, 2938, 2866, 1595, 1496, 1223, $1147 \mathrm{~cm}^{-1} .{ }^{1} \mathrm{H}$ NMR (400 MHz, $\mathrm{CDCl}_{3}$ ): $\delta=7.62-7.48(\mathrm{~m}, 4 \mathrm{H}), 6.95-6.89(\mathrm{~d}, J=8.1 \mathrm{~Hz}, 1 \mathrm{H}), 6.85(\mathrm{~s}, 1 \mathrm{H})$, $6.64(\mathrm{~d}, J=8.1 \mathrm{~Hz}, 1 \mathrm{H}), 6.47(\mathrm{~d}, J=9.7 \mathrm{~Hz}, 1 \mathrm{H}), 5.68(\mathrm{~d}, J=$ $9.7 \mathrm{~Hz}, 1 \mathrm{H}), 3.41$ (d, $J=16.5 \mathrm{~Hz}, 1 \mathrm{H}), 3.08-2.89$ (m, 2H), 2.79$2.70(\mathrm{~m}, 1 \mathrm{H}), 2.40-2.31(\mathrm{~m}, 1 \mathrm{H}), 2.44(\mathrm{~s}, 3 \mathrm{H}), 1.96-1.85(\mathrm{~m}, 1 \mathrm{H})$. ${ }^{13} \mathrm{C}$ NMR $\left(100 \mathrm{MHz}, \mathrm{CDCl}_{3}\right): \delta=149.9,141.9,135.4,134.6$, $130.9,130.7,130.0,129.8,128.0,127.1,124.6,124.1,121.1$, 116.3, 75.7, 33.5, 32.2, 20.5, 18.0. MS (ESI) $m / z(\%)=364$ (100) $[\mathrm{M}+\mathrm{H}]^{+}$. Anal. calcd for $\mathrm{C}_{21} \mathrm{H}_{18} \mathrm{ClN}_{3} \mathrm{O}: \mathrm{C}, 69.32 ; \mathrm{H}, 4.99 ; \mathrm{N}$, 11.55. Found: C, 69.30; H, 4.97; N, 11.59.

1-(4-Methoxyphenyl)-6' -methyl-1,4,6,7-tetrahydrospiro[benzo[d] [1,2,3]triazole-5,2'-chromene] (7d). White solid; yield: 42\%; mp $116-118{ }^{\circ} \mathrm{C} ; R_{\mathrm{f}}=0.22$ (PE/EtOAc $5: 2$ ). IR (KBr): 3015, 2924, 2854, 1590, 1482, 1252, $1149 \mathrm{~cm}^{-1} .{ }^{1} \mathrm{H}$ NMR (400 MHz, $\left.\mathrm{CDCl}_{3}\right): \delta=7.50$ $(\mathrm{d}, J=9.0 \mathrm{~Hz}, 2 \mathrm{H}), 7.03(\mathrm{~d}, J=9.0 \mathrm{~Hz}, 2 \mathrm{H}), 6.91(\mathrm{~d}, J=8.1 \mathrm{~Hz}, 1 \mathrm{H})$, $6.85(\mathrm{~s}, 1 \mathrm{H}), 6.65(\mathrm{~d}, J=8.1 \mathrm{~Hz}, 1 \mathrm{H}), 6.46(\mathrm{~d}, J=9.7 \mathrm{~Hz}, 1 \mathrm{H}), 5.68(\mathrm{~d}$, $J=9.7 \mathrm{~Hz}, 1 \mathrm{H}), 3.88(\mathrm{~s}, 3 \mathrm{H}), 3.40$ (d, $J=16.4 \mathrm{~Hz}, 1 \mathrm{H}), 3.01-2.91(\mathrm{~m}$, 2H), 2.75-2.66 (m, 1H), 2.36-2.29 (m, 1H), 2.26 (s, 3H), 1.96-1.85 (m, 1H). ${ }^{13} \mathrm{C} \mathrm{NMR}\left(100 \mathrm{MHz}, \mathrm{CDCl}_{3}\right): \delta=159.8,149.9,141.4,131.0$, 130.6, 129.9, 129.9, 128.1, 127.1, 124.6, 124.5, 121.2, 116.3, 114.6, 75.9, 55.6, 33.7, 32.2, 20.5, 17.8. MS (ESI) $m / z(\%)=360$ (100) $[\mathrm{M}+$ $\mathrm{H}]^{+}$. Anal. calcd for $\mathrm{C}_{22} \mathrm{H}_{21} \mathrm{~N}_{3} \mathrm{O}_{2}: \mathrm{C}, 73.52 ; \mathrm{H}, 5.89 ; \mathrm{N}, 11.69$. Found: C, 73.56; H, 5.90; N, 11.64 .

1-Benzyl-6'-methyl-1,4,6,7-tetrahydrospiro[benzo[ $d][1,2,3]$ triazole-5, $\mathbf{2}^{\prime}$-chromene] (7e). White solid; yield: $36 \%$; mp 158$160{ }^{\circ} \mathrm{C} ; R_{\mathrm{f}}=0.14$ (PE/EtOAc $\left.5: 2\right)$. IR (KBr): 3025, 2937, 2855, 1590, 1488, 1221, $1111 \mathrm{~cm}^{-1} \cdot{ }^{1} \mathrm{H}$ NMR (400 MHz, $\left.\mathrm{CDCl}_{3}\right): \delta=$ $7.40-7.30(\mathrm{~m}, 3 \mathrm{H}), 7.23-7.18(\mathrm{~m}, 2 \mathrm{H}), 6.88(\mathrm{dd}, J=8.2,1.7 \mathrm{~Hz}$, $1 \mathrm{H}), 6.81(\mathrm{~d}, J=1.8 \mathrm{~Hz}, 1 \mathrm{H}), 6.51(\mathrm{~d}, J=8.1 \mathrm{~Hz}, 1 \mathrm{H}), 6.41(\mathrm{~d}, J=$ $9.7 \mathrm{~Hz}, 1 \mathrm{H}), 5.60(\mathrm{~d}, J=9.7 \mathrm{~Hz}, 1 \mathrm{H}), 5.59(\mathrm{~d}, J=2.4 \mathrm{~Hz}, 2 \mathrm{H}), 3.31$ $(\mathrm{d}, J=16.4 \mathrm{~Hz}, 1 \mathrm{H}), 2.87(\mathrm{~d}, J=16.4 \mathrm{~Hz}, 1 \mathrm{H}), 2.67-2.54(\mathrm{~m}, 1 \mathrm{H})$, 2.49-2.39 (m, 1H), 2.24 (s, 3H), $2.20(\mathrm{~m}, 1 \mathrm{H}), 1.89-1.78(\mathrm{~m}, 1 \mathrm{H})$. ${ }^{13} \mathrm{C} \mathrm{NMR}\left(100 \mathrm{MHz}, \mathrm{CDCl}_{3}\right): \delta=149.8,141.5,134.8,131.0$, $130.6,129.8,130.0,128.4,128.0,127.4,127.0,124.4,121.2$, 116.2, 75.9, 52.0, 33.6, 31.8, 20.5, 16.5. MS (ESI) $m / z(\%)=344$ (100) $[\mathrm{M}+\mathrm{H}]^{+}$. Anal. calcd for $\mathrm{C}_{22} \mathrm{H}_{21} \mathrm{~N}_{3} \mathrm{O}: \mathrm{C}, 76.94 ; \mathrm{H}, 6.16 ; \mathrm{N}$, 12.24. Found: C, 76.89; H, 6.18; N, 12.27.

6'-Chloro-1-phenyl-1,4,6,7-tetrahydrospiro[benzo[d][1,2,3]-triazole-5,2'-chromene] (7f). White solid; yield: 45\%; mp 128$130{ }^{\circ} \mathrm{C} ; R_{\mathrm{f}}=0.28$ (PE/EtOAc $5: 2$ ). IR (KBr): 3026, 2929, 2845, 1588, 1463, 1206, $1109 \mathrm{~cm}^{-1} .{ }^{1} \mathrm{H}$ NMR (400 MHz, $\left.\mathrm{CDCl}_{3}\right): \delta=$ $7.64-7.45$ (m, 5H), 7.07 (dd, $J=8.5,2.5 \mathrm{~Hz}, 1 \mathrm{H}), 7.02$ (d, $J=$ $2.5 \mathrm{~Hz}, 1 \mathrm{H}), 6.69$ (d, J=8.5 Hz, 1H), 6.45 (d, $J=9.8 \mathrm{~Hz}, 1 \mathrm{H}), 5.76$ $(\mathrm{d}, J=9.8 \mathrm{~Hz}, 1 \mathrm{H}), 3.41$ (d, $J=16.7 \mathrm{~Hz}, 1 \mathrm{H}), 3.09-2.94(\mathrm{~m}, 2 \mathrm{H})$, 2.84-2.75 (m, 1H), 2.39-2.31 (m, 1H), 1.99-1.89 (m, 1H). ${ }^{13} \mathrm{C}$ NMR (100 MHz, $\left.\mathrm{CDCl}_{3}\right): \delta=150.6,141.3,136.8,130.8,129.6$, 129.3, 129.1, 128.8, 126.2, 126.2, 123.5, 123.0, 122.7, 117.8, 76.4, 33.6, 32.4, 18.0. MS (ESI) $m / z(\%)=350(100)[\mathrm{M}+\mathrm{H}]^{+}$. Anal. calcd for $\mathrm{C}_{20} \mathrm{H}_{16} \mathrm{ClN}_{3} \mathrm{O}$ : C, 68.67; H, 4.61; N, 12.01. Found: C, $68.65 ; \mathrm{H}, 4.60 ; \mathrm{N}, 12.04$.

$6^{\prime}$-Chloro-1-(p-tolyl)-1,4,6,7-tetrahydrospiro[benzo[d][1,2,3]-triazole-5,2'-chromene] (7g). White solid; yield: 60\%; mp 116$168{ }^{\circ} \mathrm{C} ; R_{\mathrm{f}}=0.28$ (PE/EtOAc $5: 2$ ). IR (KBr): 3033, 2931, 2847, 1591, 1477, 1209, $1117 \mathrm{~cm}^{-1} .{ }^{1} \mathrm{H}$ NMR (400 MHz, $\left.\mathrm{CDCl}_{3}\right): \delta=$ 7.50-7.45 (m, 2H), 7.36, $7.31(\mathrm{~m}, 2 \mathrm{H}), 7.06(\mathrm{dd}, J=8.5,2.5 \mathrm{~Hz}$, $1 \mathrm{H}), 7.02(\mathrm{~d}, J=2.5 \mathrm{~Hz}, 1 \mathrm{H}), 6.69$ (d, $J=8.5 \mathrm{~Hz}, 1 \mathrm{H}), 6.44$ (d, $J=$ $9.8 \mathrm{~Hz}, 1 \mathrm{H}), 5.75$ (d, $J=9.8 \mathrm{~Hz}, 1 \mathrm{H}), 3.40(\mathrm{~d}, J=17.0 \mathrm{~Hz}, 1 \mathrm{H})$, 3.05-2.93 (m, 2H), 2.80-2.72 (m, 1H), $2.44(\mathrm{~s}, 3 \mathrm{H}), 2.37-2.30(\mathrm{~m}$, $1 \mathrm{H}), 1.93(\mathrm{~m}, 1 \mathrm{H}) .{ }^{13} \mathrm{C} \mathrm{NMR}\left(100 \mathrm{MHz}, \mathrm{CDCl}_{3}\right): \delta=150.7,141.1$, $139.0,134.4,130.7,130.1,129.3,129.1,126.2$, 123.5, 122.9, $122.7,117.8,76.5,33.6,32.4,21.2,17.9$. MS (ESI) $m / z(\%)=364$ (100) $[\mathrm{M}+\mathrm{H}]^{+}$. Anal. calcd for $\mathrm{C}_{21} \mathrm{H}_{18} \mathrm{ClN}_{3} \mathrm{O}: \mathrm{C}, 69.32 ; \mathrm{H}, 4.99 ; \mathrm{Cl}$, 9.74; N, 11.55. Found: C, 69.30; H, 4.97; Cl, 9.74; N, 11.59 .

6'-Chloro-1-(4-chlorophenyl)-1,4,6,7-tetrahydrospiro[benzo[d][1,2,3]triazole-5, $\mathbf{2}^{\prime}$-chromene] (7h). White solid; yield: 54\%; mp $142-144{ }^{\circ} \mathrm{C} ; R_{\mathrm{f}}=0.37$ (PE/EtOAc $5: 2$ ). IR (KBr): 3016, 2955, 2847, 1589, 1486, 1219, $1102 \mathrm{~cm}^{-1} \cdot{ }^{1} \mathrm{H}$ NMR (400 MHz, $\left.\mathrm{CDCl}_{3}\right): \delta=$ $7.60-7.49(\mathrm{~m}, 4 \mathrm{H}), 7.06$ (dd, $J=8.5,2.6 \mathrm{~Hz}, 1 \mathrm{H}), 7.02(\mathrm{~d}, J=$ $2.6 \mathrm{~Hz}, 1 \mathrm{H}), 6.68(\mathrm{~d}, J=8.5 \mathrm{~Hz}, 1 \mathrm{H}), 6.45(\mathrm{~d}, J=9.8 \mathrm{~Hz}, 1 \mathrm{H}), 5.75$ $(\mathrm{d}, J=9.8 \mathrm{~Hz}, 1 \mathrm{H}), 3.41$ (d, $J=16.6 \mathrm{~Hz}, 1 \mathrm{H}), 3.07-2.90(\mathrm{~m}, 2 \mathrm{H})$, 2.82-2.73 (m, 1H), 2.40-2.31 (m, 1H), 1.98-1.88 (m, 1H). ${ }^{13} \mathrm{C} \mathrm{NMR}$ $\left(100 \mathrm{MHz}, \mathrm{CDCl}_{3}\right): \delta=150.6,141.6,135.3,134.7,130.8,129.8$, 129.1, 126.3, 124.1, 123.6, 122.6, 117.8, 76.3, 33.5, 32.3, 18.0. MS (ESI) $m / z(\%)=384(100)[\mathrm{M}+\mathrm{H}]^{+}$. Anal. calcd for $\mathrm{C}_{20} \mathrm{H}_{15} \mathrm{Cl}_{2} \mathrm{~N}_{3} \mathrm{O}$ : C, 62.51; H, 3.93; N, 10.94. Found: C, 62.55; H, 3.92; N, 10.91. 
6'-Chloro-1-(4-methoxyphenyl)-1,4,6,7-tetrahydrospiro[benzo[d][1,2,3]triazole-5, $\mathbf{2}^{\prime}$-chromene] (7i). White solid; yield: 36\%; mp 138$140{ }^{\circ} \mathrm{C} ; R_{\mathrm{f}}=0.14$ (PE/EtOAc $5: 2$ ). IR (KBr): 3012, 2942, 2841, 1604, 1476, 1219, $1114 \mathrm{~cm}^{-1} .{ }^{1} \mathrm{H}$ NMR (400 MHz, $\left.\mathrm{CDCl}_{3}\right): \delta=7.54-7.46$ $(\mathrm{m}, 2 \mathrm{H}), 7.09-7.00(\mathrm{~m}, 4 \mathrm{H}), 6.68(\mathrm{~d}, J=8.5 \mathrm{~Hz}, 1 \mathrm{H}), 6.44(\mathrm{~d}, J=$ $9.8 \mathrm{~Hz}, 1 \mathrm{H}), 5.76(\mathrm{~d}, J=9.8 \mathrm{~Hz}, 1 \mathrm{H}), 3.88(\mathrm{~s}, 3 \mathrm{H}), 3.40$ (d, $J=$ $16.1 \mathrm{~Hz}, 1 \mathrm{H}), 3.02-2.90(\mathrm{~m}, 2 \mathrm{H}), 2.79-2.68(\mathrm{~m}, 1 \mathrm{H}), 2.37-2.29(\mathrm{~m}$, 1H), $1.98-1.88(\mathrm{~m}, 1 \mathrm{H}) .{ }^{13} \mathrm{C}$ NMR $\left(100 \mathrm{MHz}, \mathrm{CDCl}_{3}\right): \delta=159.9$, 150.7, 141.0, 130.9, 129.3, 129.1, 126.2, 124.6, 123.5, 117.8, 114.7, 76.5, 55.6, 33.6, 32.4, 17.7. MS (ESI) $m / z(\%)=380(100)[\mathrm{M}+\mathrm{H}]^{+}$. Anal. calcd for $\mathrm{C}_{21} \mathrm{H}_{18} \mathrm{ClN}_{3} \mathrm{O}_{2}$ : C, 66.40; H, 4.78; N, 11.06. Found: C, 66.45; H, 4.77; N, 11.10.

1-Benzyl-6'-chloro-1,4,6,7-tetrahydrospiro[benzo $[d][1,2,3]$ triazole-5,2'-chromene] (7j). White solid; yield: $54 \%$; mp $114-$ $116{ }^{\circ} \mathrm{C} ; R_{\mathrm{f}}=0.10$ (PE/EtOAc $\left.5: 2\right)$. IR (KBr): 3040, 2941, 2865, $1588,1482,1208,1112 \mathrm{~cm}^{-1} .{ }^{1} \mathrm{H}$ NMR $\left(400 \mathrm{MHz}, \mathrm{CDCl}_{3}\right): \delta={ }^{1} \mathrm{H}$ NMR $\left(400 \mathrm{MHz}, \mathrm{CDCl}_{3}\right) \delta 7.40-7.31(\mathrm{~m}, 3 \mathrm{H}), 7.23-7.17(\mathrm{~m}, 2 \mathrm{H})$, 7.04-7.00 (dd, $J=8.5,2.5 \mathrm{~Hz}, 1 \mathrm{H}), 6.99-6.97(\mathrm{~d}, J=2.5 \mathrm{~Hz}, 1 \mathrm{H})$, $6.54(\mathrm{~d}, J=8.5 \mathrm{~Hz}, 1 \mathrm{H}), 6.39(\mathrm{~d}, J=9.8 \mathrm{~Hz}, 1 \mathrm{H}), 5.67(\mathrm{~d}, J=$ $9.8 \mathrm{~Hz}, 1 \mathrm{H}), 5.49(\mathrm{~d}, J=3.1 \mathrm{~Hz}, 2 \mathrm{H}), 3.29(\mathrm{~d}, J=16.5 \mathrm{~Hz}, 1 \mathrm{H})$, $2.88(\mathrm{~d}, J=16.5 \mathrm{~Hz}, 1 \mathrm{H}), 2.66-2.54(\mathrm{~m}, 1 \mathrm{H}), 2.52-2.42(\mathrm{~m}, 1 \mathrm{H})$, 2.26-2.17 (m, 1H), 1.90-1.81 (m, 1H). ${ }^{13} \mathrm{C}$ NMR (100 MHz, $\left.\mathrm{CDCl}_{3}\right): \delta=150.6,141.2,134.7,130.9,129.2,129.0,128.4,127.4$, 126.1, 126.1, 123.4, 122.7, 117.7, 76.5, 52.1, 33.5, 31.9, 16.5. MS (ESI) $m / z(\%)=364(100)[\mathrm{M}+\mathrm{H}]^{+}$. Anal. calcd for $\mathrm{C}_{21} \mathrm{H}_{18} \mathrm{ClN}_{3} \mathrm{O}$ : C, 69.32; H, 4.99; N, 11.55; O, 4.40. Found: C, 69.38; H, 4.97; N, 11.59 .

6'-Chloro-7'-methyl-1-phenyl-1,4,6,7-tetrahydrospiro[benzo[d][1,2,3]triazole-5, $\mathbf{2}^{\prime}$-chromene] (7k). White solid; yield: $54 \%$; $\mathrm{mp}$ $156-158{ }^{\circ} \mathrm{C} ; R_{\mathrm{f}}=0.31$ (PE/EtOAc $5: 2$ ). IR (KBr): 3076, 2921, 2849, 1600, 1494, 1251, $1158 \mathrm{~cm}^{-1} .{ }^{1} \mathrm{H}$ NMR $\left(400 \mathrm{MHz}, \mathrm{CDCl}_{3}\right): \delta=$ 7.64-7.45 (m, 5H), $7.01(\mathrm{~s}, 1 \mathrm{H}), 6.65(\mathrm{~s}, 1 \mathrm{H}), 6.43(\mathrm{~d}, J=9.8 \mathrm{~Hz}$, $1 \mathrm{H}), 5.70(\mathrm{~d}, J=9.8 \mathrm{~Hz}, 1 \mathrm{H}), 3.40(\mathrm{~d}, J=16.5 \mathrm{~Hz}, 1 \mathrm{H}), 3.08-2.91$ (m, 2H), 2.83-2.75 (m, 1H), 2.39-2.30 (m, 1H), $2.28(\mathrm{~s}, 3 \mathrm{H}), 1.97-$ $1.87(\mathrm{~m}, 1 \mathrm{H}) .{ }^{13} \mathrm{C} \mathrm{NMR}\left(100 \mathrm{MHz}, \mathrm{CDCl}_{3}\right): \delta=150.5,141.4,137.2$, 136.8, 130.8, 129.6, 128.8, 128.3, 126.5, 126.3, 123.4, 123.0, 120.5, 118.9, 76.3, 33.5, 32.3, 20.1, 18.0. MS (ESI) $m / z(\%)=364(100)[\mathrm{M}$ $+\mathrm{H}]^{+}$. Anal. calcd for $\mathrm{C}_{21} \mathrm{H}_{18} \mathrm{ClN}_{3} \mathrm{O}: \mathrm{C}, 69.32 ; \mathrm{H}, 4.99 ; \mathrm{N}, 11.55$. Found: C, 69.35; H, 4.98; N, 11.57 .

$6^{\prime}$-Chloro-7'-methyl-1-(p-tolyl)-1,4,6,7-tetrahydrospiro[benzo[d][1,2,3]triazole-5, $2^{\prime}$-chromene] (7l). White solid; yield: $57 \%$; mp 208-210 ${ }^{\circ} \mathrm{C} ; R_{\mathrm{f}}=0.34$ (PE/EtOAc $5: 2$ ). IR (KBr): 3081, 2926, 2864, $1605,1488,1256,1158 \mathrm{~cm}^{-1} .{ }^{1} \mathrm{H}$ NMR $\left(400 \mathrm{MHz}, \mathrm{CDCl}_{3}\right): \delta=7.51-$ $7.46(\mathrm{~m}, 2 \mathrm{H}), 7.31-7.36(\mathrm{~m}, 2 \mathrm{H}), 7.01(\mathrm{~s}, 1 \mathrm{H}), 6.65(\mathrm{~s}, 1 \mathrm{H}), 6.42(\mathrm{~d}, J$ $=9.8 \mathrm{~Hz}, 1 \mathrm{H}), 5.69(\mathrm{~d}, J=9.8 \mathrm{~Hz}, 1 \mathrm{H}), 3.39(\mathrm{~d}, J=16.6 \mathrm{~Hz}, 1 \mathrm{H})$, 3.04-2.91 (m, 2H), 2.80-2.72 (m, 1H), $2.44(\mathrm{~s}, 3 \mathrm{H}), 2.37-2.29(\mathrm{~m}$, $1 \mathrm{H}), 2.28(\mathrm{~s}, 3 \mathrm{H}), 1.97-1.87(\mathrm{~m}, 1 \mathrm{H}) .{ }^{13} \mathrm{C}$ NMR $\left(100 \mathrm{MHz}, \mathrm{CDCl}_{3}\right)$ : $\delta=150.5,141.3$, 138.9, 137.1, 134.4, 130.8, 130.1, 128.3, 126.4, 126.3, 123.4, 122.9, 120.5, 118.9, 76.3, 33.6, 32.3, 21.2, 20.1, 17.9. MS (ESI) $m / z(\%)=378(100)[\mathrm{M}+\mathrm{H}]^{+}$. Anal. calcd for $\mathrm{C}_{22} \mathrm{H}_{20} \mathrm{ClN}_{3} \mathrm{O}$ : C, 69.93; H, 5.33; N, 11.12. Found: C, 69.97; H, 5.35; N, 11.06 .

6'-Chloro-1-(4-chlorophenyl)-7'-methyl-1,4,6,7-tetrahydrospiro[benzo[d][1,2,3]triazole-5, $\mathbf{2}^{\prime}$-chromene] $(7 \mathrm{~m})$. White solid; yield: $68 \% ; \mathrm{mp} 182-184{ }^{\circ} \mathrm{C} ; R_{\mathrm{f}}=0.40$ (PE/EtOAc $5: 2$ ). IR (KBr): 3089 , 2922, 2848, 1606, 1494, 1257, $1156 \mathrm{~cm}^{-1} .{ }^{1} \mathrm{H}$ NMR $(400 \mathrm{MHz}$, $\left.\mathrm{CDCl}_{3}\right): \delta=7.60-7.49(\mathrm{~m}, 4 \mathrm{H}), 7.01(\mathrm{~s}, 1 \mathrm{H}), 6.64(\mathrm{~s}, 1 \mathrm{H}), 6.44(\mathrm{~d}, J=$
$9.8 \mathrm{~Hz}, 1 \mathrm{H}), 5.69(\mathrm{~d}, J=9.8 \mathrm{~Hz}, 1 \mathrm{H}), 3.40(\mathrm{~d}, J=16.6 \mathrm{~Hz}, 1 \mathrm{H}), 3.07-$ $2.89(\mathrm{~m}, 2 \mathrm{H}), 2.82-2.73(\mathrm{~m}, 1 \mathrm{H}), 2.39-2.32(\mathrm{~m}, 1 \mathrm{H}), 2.28(\mathrm{~s}, 3 \mathrm{H})$, 1.96-1.87 (m, 1H). ${ }^{13} \mathrm{C}$ NMR (100 MHz, $\left.\mathrm{CDCl}_{3}\right): \delta=150.4,141.7$, 137.2, 135.3, 134.7, 130.8, 129.8, 128.2, 126.5, 126.3, 124.1, 123.5, 120.5, 118.8, 76.1, 33.4, 32.3, 20.1, 18.0. MS (ESI) $\mathrm{m} / \mathrm{z}(\%)=398$ (100) $[\mathrm{M}+\mathrm{H}]^{+}$. Anal. calcd for $\mathrm{C}_{21} \mathrm{H}_{17} \mathrm{Cl}_{2} \mathrm{~N}_{3} \mathrm{O}: \mathrm{C}, 63.33 ; \mathrm{H}, 4.30 ; \mathrm{N}$, 10.55. Found: C, 63.31; H, 4.29; N, 10.58 .

6'-Chloro-1-(4-methoxyphenyl)-7'-methyl-1,4,6,7-tetrahydrospiro [benzo[d][1,2,3]triazole-5,2'-chromene] (7n). White solid; yield: $38 \%$; mp $148-150{ }^{\circ} \mathrm{C} ; R_{\mathrm{f}}=0.17$ (PE/EtOAc $5: 2$ ). IR (KBr): 3058 , 2926, 2844, 1609, 1445, 1256, $1159 \mathrm{~cm}^{-1} .{ }^{1} \mathrm{H}$ NMR $(400 \mathrm{MHz}$, $\left.\mathrm{CDCl}_{3}\right): \delta=7.55-7.47(\mathrm{~m}, 2 \mathrm{H}), 7.07-6.99(\mathrm{~m}, 3 \mathrm{H}), 6.64(\mathrm{~s}, 1 \mathrm{H}), 6.43$ (d, $J=9.8 \mathrm{~Hz}, 1 \mathrm{H}), 5.70(\mathrm{~d}, J=9.8 \mathrm{~Hz}, 1 \mathrm{H}), 3.88(\mathrm{~s}, 3 \mathrm{H}), 3.39(\mathrm{~d}, J=$ $16.6 \mathrm{~Hz}, 1 \mathrm{H}), 3.01-2.90(\mathrm{~m}, 2 \mathrm{H}), 2.78-2.68(\mathrm{~m}, 1 \mathrm{H}), 2.37-2.28(\mathrm{~m}$, $1 \mathrm{H}), 2.28(\mathrm{~s}, 3 \mathrm{H}), 1.96-1.87(\mathrm{~m}, 1 \mathrm{H}) .{ }^{13} \mathrm{C}$ NMR $\left(100 \mathrm{MHz}, \mathrm{CDCl}_{3}\right)$ : $\delta=159.8,150.5,141.1,137.1,130.9,129.9,128.3,126.4,126.3$, 124.6, 123.4, 120.5, 118.9, 114.7, 76.3, 55.6, 33.6, 32.3, 20.1, 17.7. MS (ESI) $m / z(\%)=394(100)[\mathrm{M}+\mathrm{H}]^{+}$. Anal. calcd for $\mathrm{C}_{22} \mathrm{H}_{20} \mathrm{ClN}_{3} \mathrm{O}_{2}$ : C, 67.09; H, 5.12; N, 10.67. Found: C, 67.12; H, 5.13; N, 10.71.

1-Benzyl-6'-chloro-7'-methyl-1,4,6,7-tetrahydrospiro[benzo[d][1,2,3]triazole-5,2'-chromene] (7o). White solid; yield: $42 \%$; mp $184-186^{\circ} \mathrm{C} ; R_{\mathrm{f}}=0.11$ (PE/EtOAc $5: 2$ ). IR (KBr): 3053, 2924, 2851, 1602, 1490, 1252, $1156 \mathrm{~cm}^{-1} .{ }^{1} \mathrm{H}$ NMR $\left(400 \mathrm{MHz}, \mathrm{CDCl}_{3}\right): \delta=$ 7.41-7.32 (m, 3H), 7.23-7.18 (m, 2H), $6.97(\mathrm{~s}, 1 \mathrm{H}), 6.49(\mathrm{~s}, 1 \mathrm{H})$, $6.37(\mathrm{~d}, J=9.8 \mathrm{~Hz}, 1 \mathrm{H}), 5.61(\mathrm{~d}, J=9.8 \mathrm{~Hz}, 1 \mathrm{H}), 5.49(\mathrm{~d}, J=$ $6.0 \mathrm{~Hz}, 2 \mathrm{H}), 3.29(\mathrm{~d}, J=16.4 \mathrm{~Hz}, 1 \mathrm{H}), 2.86(\mathrm{~d}, J=16.4 \mathrm{~Hz}, 1 \mathrm{H})$, 2.67-2.56 (m, 1H), 2.50-2.41 (m, 1H), $2.24(\mathrm{~s}, 3 \mathrm{H}), 2.17-2.34(\mathrm{~m}$, 1H), $1.89-1.79(\mathrm{~m}, 1 \mathrm{H}) .{ }^{13} \mathrm{C}$ NMR $\left(100 \mathrm{MHz}, \mathrm{CDCl}_{3}\right): \delta=150.4$, 141.3, 137.0, 134.8, 130.9, 129.0, 128.4, 128.2, 127.5, 126.4, 126.2, 123.3, 120.5, 118.8, 76.3, 52.1, 33.5, 31.9, 20.1, 16.5. MS (ESI) $\mathrm{m} / \mathrm{z}$ $(\%)=378(100)[\mathrm{M}+\mathrm{H}]^{+}$. Anal. calcd for $\mathrm{C}_{22} \mathrm{H}_{20} \mathrm{ClN}_{3} \mathrm{O}: \mathrm{C}, 69.93$; H, 5.33; N, 11.12. Found: C, 69.99; H, 5.30; N, 11.09.

\section{Conclusion}

In conclusion, a series of 1,2,3-triazole-fused spirochromene motifs were synthesized for the first time in four steps via $[3+2]$ Huisgen cycloaddition starting from 2-hydroxy acetophenone and all these new compounds were confirmed by ${ }^{1} \mathrm{H}$ NMR, ${ }^{13} \mathrm{C}$ NMR, IR and MS spectra. The single X-ray diffraction study was used to confirm the molecular structure of a representative compound 7a unambiguously. The in vitro antimycobacterial evaluation showed that most of the synthesized 1,2,3-triazolefused spirochromenes exhibited moderate to good antimycobacterial activity. Noticeably, compounds $7 \mathbf{7 a}, 7 \mathbf{d}$ and $7 \mathbf{i}$ most potent compound in vitro with MIC of $1.56 \mu \mathrm{g}$, against MTB. These findings demonstrated that 1,2,3-triazole-fused spirochromenes have biological significance; further optimization of these identified hits as well as structural modifications are in progress in order to enhance the efficacy against $M$. tuberculosis.

\section{Conflicts of interest}

There are no conflicts to declare. 


\section{Acknowledgements}

The authors thank The Head, Department of Chemistry, Osmania University, Hyderabad, for providing laboratory facilities. P. Chiranjeevi grateful to UGC, New Delhi for PhD fellowship. We thank CFRD analytical team for providing spectral analysis facilities.

\section{Notes and references}

1 World Health Organization, Global tuberculosis report, 2017, only available online: http://www.who.int/tb/publications/ global_report/en.

2 World Health Organization, Global tuberculosis report, 2013, only available online: http://apps.who.int/iris/bitstream/ 10665/91355/1/9789241564656_eng.pdf.

3 A. Pawlowski, M. Jansson, M. Sköld, M. E. Rottenberg and G. Källenius, PLoS Pathog., 2012, 8, e1002464.

4 R. Loddenkemper, D. Sagebiel and A. Brendel, Eur. Respir. J., 2002, (suppl. 36), 66s.

5 N. Boechat, V. F. Ferreira, S. B. Ferreira, M. d. L. G. Ferreira, F. d. C. da Silva, M. M. Bastos, M. d. S. Costa, M. C. S. Lourenço, A. C. Pinto, A. U. Krettli, A. C. Aguiar, B. M. Teixeira, N. V. da Silva, P. R. C. Martins, F. A. F. M. Bezerra, A. L. S. Camilo, G. P. da Silva and C. C. P. Costa, J. Med. Chem., 2011, 54, 5988.

6 D. Cappoen, P. Claes, J. Jacobs, R. Anthonissen, V. Mathys, L. Verschaeve, K. Huygen and N. D. Kimpe, J. Med. Chem., 2014, 57, 2895.

7 Y. Zhang, K. Post-Martens and S. Denkin, Drug Discovery Today, 2006, 11, 21.

8 Y. Kashman, K. R. Gustafson, R. W. Fuller, J. H. Cardellina 2nd, J. B. McMahon, M. J. Currens, R. W. Buckheit Jr, S. H. Hughes, G. M. Cragg and M. R. Boyd, J. Med. Chem., 1992, 35, 2735.

9 M. T. Flavin, J. D. Rizzo, A. Khilevich, A. Kucherenko, A. K. Sheinkman, V. Vilaychack, L. Lin, W. Chen, E. M. Greenwood, T. Pengsuparp, J. M. Pezzuto, S. H. Hughes, T. M. Flavin, M. Cibulski, W. A. Boulanger, R. L. Shone and Z. Q. Xu, J. Med. Chem., 1996, 39, 1303.

10 Y. Kashiwada, K. Yamazaki, Y. Ikeshiro, T. Yamagishi, T. Fujioka, K. Mihashi, K. Mizuki, L. M. Cosentino, K. Fowke, S. L. Morris-Natschke and K.-H. Lee, Tetrahedron, 2001, 57, 1559.

11 J. L. Lopez-Perez, D. A. Olmedo, E. Del Olmo, Y. Vasquez, P. N. Solis, M. P. Gupta and A. San Feliciano, J. Nat. Prod., 2005, 68, 369.

12 D. J. Chang, H. An, K. S. Kim, H. H. Kim, J. Jung, J. M. Lee, N. J. Kim, Y. T. Han, H. Yun, S. Lee, G. Lee, S. Lee, J. S. Lee, J. H. Cha, J. H. Park, J. W. Park, S. C. Lee, S. G. Kim, J. H. Kim, H. Y. Lee, K. W. Kim and Y. G. Suh, J. Med. Chem., 2012, 55, 10863.

13 C. W. Brown, S. Liu, J. Klucik, K. D. Berlin, P. J. Brennan, D. Kaur and D. M. Benbrook, J. Med. Chem., 2004, 47, 1008.

14 S. Thareja, A. Verma, A. Kalra, S. Gosain, P. V. Rewatkar and G. R. Kokil, Acta Pol. Pharm., 2010, 67, 423.
15 S. J. Mohr, M. A. Chirigos, F. S. Fuhrman and J. W. Pryor, Cancer Res., 1975, 35, 3750.

16 Q.-F. Hu, B. Zhou, J.-M. Huang, X.-M. Gao, L.-D. Shu, G.-Y. Yang and C.-T. Che, J. Nat. Prod., 2013, 76, 292.

17 S.-Y. Cheng, K.-J. Huang, S.-K. Wang, Z.-H. Wen, P.-W. Chen and C.-Y. Duh, J. Nat. Prod., 2010, 73, 771.

18 W. Gregor, G. Grabner, C. Adelwöhrer, T. Rosenau and L. Gille, J. Org. Chem., 2005, 70, 3472.

19 S. Sutthivaiyakit, O. Thongnak, T. Lhinhatrakool, O. Yodchun, R. Srimark, P. Dowtaisong and M. Chuankamnerdkarn, J. Nat. Prod., 2009, 72, 1092.

20 P.-C. Pan, M.-J. Cheng, C.-F. Peng, H.-Y. Huang, J.-J. Chen and I.-S. Chen, J. Nat. Prod., 2010, 73, 890.

21 Z. Q. Xu, W. W. Barrow, W. J. Suling, L. Westbrook, E. Barrow, Y. M. Lin and M. T. Flavin, Bioorg. Med. Chem., 2004, 12, 1199.

22 A. Termentzi, I. Khouri, T. Gaslonde, S. Prado, B. SaintJoanis, F. Bardou, E. P. Amanatiadou, I. S. Vizirianakis, J. Kordulakova, M. Jackson, R. Brosch, Y. L. Janin, M. Daffé, F. Tillequin and S. Michel, Eur. J. Med. Chem., 2010, 45, 5833.

23 N. Siddiqui, W. Ahsan, M. S. Alam, R. Alia, S. Jain, B. Azad and J. Akhtar, Int. J. Pharm. Sci. Rev. Res., 2011, 8, 161.

24 G. Biagi, I. Giorgi, O. Livi, V. Scartoni, L. Betti, G. Giannaccini and M. L. Trincavelli, Eur. J. Med. Chem., 2002, 37, 565.

25 L. Bertelli, G. Biagi, I. Giorgi, C. Manera, O. Livi, V. Scartoni, L. Betti, G. Giannaccini, L. Trincavelli and P. L. Barili, Eur. J. Med. Chem., 1998, 33, 113.

26 B. Whittaker, C. Steele, D. Hardick, M. Dale, V. Pomel, A. Quattropani, D. Beher, Eur. Pat. Appl., EP 2687528 A1, 2014.

27 C. Menendez, S. Gau, C. Lherbet, F. Rodriguez, C. Inard, M. R. Pasca and M. Baltas, Eur. J. Med. Chem., 2011, 46, 5524.

28 C. Gill, G. Jadhav, M. Shaikh, R. Kale, A. Ghawalkar, D. Nagargoje and M. Shiradkar, Bioorg. Med. Chem. Lett., 2008, 18, 6244.

29 S. Kim, S.-N. Cho, T. Oh and P. Kim, Bioorg. Med. Chem. Lett., 2012, 22, 6844.

30 B. Zhou, Y. He, X. Zhang, J. Xu, Y. Luo, Y. Wang, S. G. Franzblau, Z. Yang, R. J. Chan, Y. Liu, J. Zheng and Z.-Y. Zhang, Proc. Natl. Acad. Sci. U. S. A., 2010, 107, 4573.

31 L. S. Kallander, Q. Lu, W. Chen, T. Tomaszek, G. Yang, D. Tew, T. D. Meek, G. A. Hofmann, C. K. Schulz-Pritchard, W. W. Smith, C. A. Janson, M. D. Ryan, G.-F. Zhang, K. O. Johanson, R. B. Kirkpatrick, T. F. Ho, P. W. Fisher, M. R. Mattern, R. K. Johnson, M. J. Hansbury, J. D. Winkler, K. W. Ward, D. F. Veber and S. K. Thompson, J. Med. Chem., 2005, 48, 5644.

32 J. Zhang, N. Redman, A. P. Litke, J. Zeng, J. Zhan, K. Y. Chan and C. W. T. Chang, Bioorg. Med. Chem., 2011, 19, 498.

33 S. Chackalamannil, M. V. Chelliah, Y. Wang and Y. Xia, WO 2 0080424222008.

34 A. Dongamanti, V. K. Aamate, M. G. Devulapally, S. Gundu, M. K. Kotni, V. Manga, S. Balasubramanian and P. Ernala, Bioorg. Med. Chem. Lett., 2015, 25, 898. 
35 A. Dongamanti, V. K. Aamate, M. G. Devulapally, S. Gundu, S. Balabadra, V. Manga, P. Yogeeswari, D. Sriram and S., Mol. Diversity, 2017, 21, 999.

36 H.-J. Kabbe and A. Widdig, Angew. Chem., Int. Ed. Engl., 1982, 21, 247.

37 H. J. Kabbe, Synthesis, 1978, 1978, 886.

$38 \mathrm{Xu}$, Zusheng From Faming Zhuanli Shenqing, 103304571, 18 Sep 2013.

39 L. W. Dillard, J. Yuan, L. Jia and Y. Zheng, PCT Int, Appl, WO 2010021680, 2010.

40 R. A. Glennon and S. M. Liebowitz, J. Med. Chem., 1982, 25, 393.

41 S. Zhou, H. Liao, M. Liu, G. Feng, B. Fu, R. Li, M. Cheng, Y. Zhao and P. Gong, Bioorg. Med. Chem., 2014, 22, 6438.
42 L. Wang, S. Peng, L. J. T. Danence, Y. Gao and J. Wang, Chem.-Eur. J., 2012, 18, 6088.

43 L. J. T. Danence, Y. Gao, M. Li, Y. Huang and J. Wang, Chem.Eur. J., 2011, 17, 3584.

44 CCDC 1820092 contains supplementary crystallographic data for the compound $7 a . \dagger$

45 L. Collins and S. G. Franzblau, Antimicrob. Agents Chemother., 1997, 41, 1004.

46 J. van Meerloo, G. J. Kaspers and J. Cloos, Methods Mol. Biol., 2011, 731, 237.

47 Bruker, APEX3, SAINT and $S A D A B S$, Bruker AXS, Inc., Madison, Wisconsin, USA, 2016.

48 G. M. Sheldrick, Acta Crystallogr., Sect. B: Struct. Sci., Cryst. Eng. Mater., 2015, C71, 3-8. 